\title{
Spectral Signatures of Moisture-Convection Feedbacks over the Indian Ocean
}

\author{
FIAZ AHMED \\ Atmospheric and Oceanic Sciences, University of California, Los Angeles, Los Angeles, California \\ COURTNEY SCHUMACHER \\ Department of Atmospheric Sciences, Texas A\&M University, College Station, Texas
}

(Manuscript received 2 May 2017, in final form 31 January 2018)

\begin{abstract}
Positive feedbacks between the cloud population and the environmental moisture field are central to theoretical expositions on the Madden-Julian oscillation (MJO). This study investigates the statistical incidence of positive moisture-convection feedbacks across multiple space and time scales over the tropical Indian Ocean. This work uses vertically integrated moisture budget terms from the ECMWF interim reanalysis [ERA-Interim (ERA-I)] in a framework proposed by Hannah et al. Positive moisture-convection feedbacks are primarily a low-frequency, low-wavenumber phenomenon with significant spectral signatures in the 32-48-day time scale. The efficacy of these feedbacks, however, is subject to horizontal moisture advection variations, whose relative importance varies with scale. Wave-filtered Tropical Rainfall Measuring Mission (TRMM) satellite precipitation is used to show that these moisture-convection feedbacks contribute more to moisture increases in the MJO than in other equatorial waves. A moving-window correlation analysis suggests that instances of moisture-convection feedbacks are more frequent in drier conditions, when column water vapor (CWV) is below its climatological mean value, with the implication that positive moisture-convection feedbacks shape the mean CWV field by moistening drier air columns, but that they are less effective in moistening already moist environments. Ground radar observations show that stratiform rain damps local CWV increases on short time scales ( $<2$ days) and therefore precludes positive moisture-convection feedbacks in high-CWV environments. Vertical coherence structures from ERA-I confirm that relatively bottom-heavy cloud ensembles (i.e., peaks between 700 and $850 \mathrm{hPa}$ ) are more effective in inducing low-frequency positive moisture-convection feedbacks than ensembles with other vertical structures. Low-frequency horizontal advective drying damps moisture increases and is strongly coherent with upper-level rising motion.
\end{abstract}

\section{Introduction}

The interaction between convection and moisture has been the subject of longstanding inquiries in tropical meteorology (Neelin and Held 1987; Tompkins 2001; Derbyshire et al. 2004; Sherwood et al. 2010). Ground observations at time scales on the order of a few hours show increases in environmental moisture preceding deep convection and precipitation (Sobel et al. 2004; Holloway and Neelin 2010; DePasquale et al. 2014). Precipitation has small autocorrelation times, removing environmental moisture in short spikes, but moist atmospheric convection often occurs in conjunction with synoptic disturbances whose length and time scales are larger than the size of the cloud ensemble under consideration. The moisture convergence associated

Corresponding author: Fiaz Ahmed, fiaz@ucla.edu with the large-scale flow can transport moisture into the precipitating region and help offset the loss from precipitation. It is possible to conceive of a situation in which a positive column moisture perturbation begets moist convection, which leads to further increases in column moisture, that is, a positive feedback between moisture and convection. Such moisture-convection feedbacks can occur on multiple time and space scales with implications for convectively coupled phenomena in the tropics.

For instance, the Madden-Julian oscillation (MJO) [see reviews in Zhang (2005) and Lau and Waliser (2012)] is a low-frequency intraseasonal phenomenon without a widely accepted mechanism for its observed properties. Several theories of the MJO, however, suggest a role for positive moisture-convection feedbacks. The "moisture mode" theory considers the MJO to be a manifestation of a destabilization of the column moisture field, usually attributed to positive feedbacks between the moisture 
and attendant convection (e.g., Raymond and Fuchs 2009; Sugiyama 2009; Sobel et al. 2001; Sobel and Maloney 2012, 2013), though other sources such as surface latent heat fluxes (Sobel and Maloney 2012; Fuchs and Raymond 2017) or horizontal moisture advection (Adames and Kim 2016) are also invoked. The discharge-recharge theory (Bladé and Hartmann 1993; Kemball-Cook and Weare 2001; Benedict and Randall 2007) proposes that a slow buildup of moist static energy by the local cloud population gradually destabilizes the environment and helps usher in the MJO active phase. The skeleton model (Majda and Stechmann 2009) also invokes the positive feedback between a low-level moisture anomaly and an envelope of synoptic activity, which subsumes the convection associated with equatorial waves. A recent version of the frictional convergence model of Wang and Rui (1990) also suggests that feedbacks between moisture and precipitation might explain the slow phase speed of the MJO (Wang and Chen 2016).

There is no direct documented evidence for the existence of positive moisture-convection feedbacks from observations, though circumstantial evidence can be found in the form of a concurrent increase in columnintegrated moisture values within the MJO active phase (Myers and Waliser 2003; Roundy and Frank 2004; Yasunaga and Mapes 2012b). One of the primary motivations for this study therefore is to explore statistical signals of positive moisture-convection feedbacks and to assess the relevance of this mechanism for the MJO.

Any discussion of moisture-convection feedbacks can be enriched by acknowledging the morphology of precipitating tropical convection as categorized into three broad types: shallow convection, deep convection, and stratiform, which constitute the mesoscale convective system (MCS), the primary form of organized convection in the tropics (Houze 2004). The evolution of an MCS is marked by a distinct transition from shallow convective to deep convective to stratiform clouds. MCSs serve as the apparent building blocks for the MJO and other forms of tropical variability (Mapes et al. 2006) and possess unique statistical relationships with column water vapor (CWV). The observed rapid pickup in precipitation with increasing $\mathrm{CWV}$ in the tropics (Bretherton et al. 2004; Peters and Neelin 2006) is dominated by an increase in stratiform rain area (Ahmed and Schumacher 2015). Shallow and deep convective clouds also exhibit a marked increase at different values of $\mathrm{CWV}$, with shallow convection picking up at low values of CWV and deep convection at higher values, although still slightly less than stratiform clouds (Ahmed and Schumacher 2017). From this perspective, CWV can be viewed as a proxy for the strength and degree of organization of convection that the environment can sustain.

The effects of the different components of the cloud population on CWV have been documented by a series of modeling studies that separate the contribution from various microphysical and diabatic heating terms to the column moist static energy (MSE) under the weak temperature gradient approximation (Chikira 2014; Wolding and Maloney 2015; Janiga and Zhang 2016; Wolding et al. 2016). These works, in concert with observation-based studies (e.g., Del Genio et al. 2012; Zermeno-Diaz et al. 2015), suggest that shallow convective, congestus, and even deep convective clouds can moisten the environment directly through cloud-top detrainment or indirectly through their diabatic heating effects. Stratiform clouds, on the other hand, are generally associated with an environment whose CWV is decreasing, presumably as a result of the wind field associated with stratiform clouds (i.e., midlevel convergence leading to mesoscale downdrafts in the lower troposphere; Zipser 1977; Houze 1997) that dries the lower troposphere (Raymond et al. 2009) and moistens the upper troposphere (Zelinka and Hartmann 2009). The different effects of the convective and stratiform components of the cloud population on CWV invoke another question that we seek to answer: What environmental conditions-and associated cloud ensemblesare more likely to support positive moisture-convection feedbacks than others?

The three tropical cloud types (shallow, deep, and stratiform) also possess canonical vertical diabatic heating and divergence modes. The use of the first and second baroclinic modes as basis functions is adequate to capture much of the variance in observed diabatic heating profiles (Schumacher et al. 2004; Hagos 2010), highlighting the ubiquity of these cloud types. Tropical synoptic-scale dynamics are also greatly influenced by these two vertical modes, which shape the structure and propagation characteristics of convectively coupled waves in the tropics (Mapes 2000, Majda and Shefter 2001, Khouider and Majda 2006; Kuang 2008). The relevance of moisture-convection feedbacks to these synoptic waves will also be assessed in this study.

Hannah et al. (2016, hereafter HME16) introduced a measure called the Lagrangian CWV tendency (LCT), which they computed as the residual between columnintegrated vertical moisture advection and precipitation in the column. They showed that LCT, when conditionally averaged by CWV values, increased with increasing CWV, which they interpreted as evidence of the existence of positive moisture-convection feedbacks in observations. In this paper we build on HME16 and 


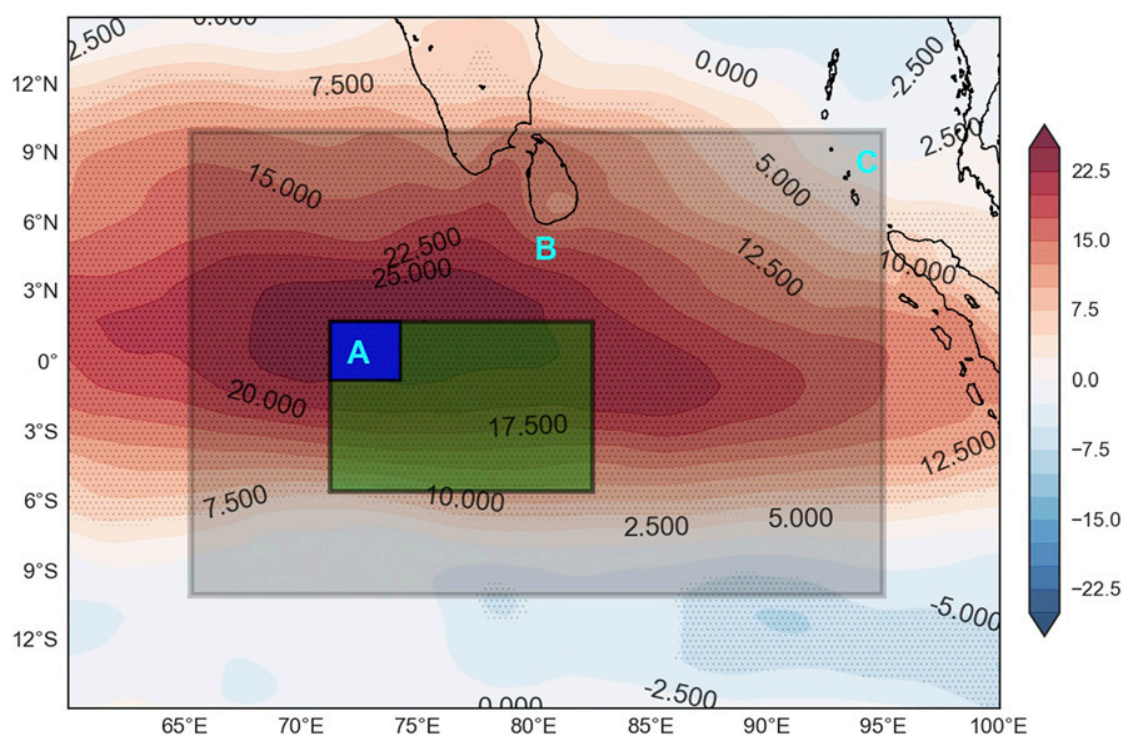

FIG. 1. The three different domain sizes used in this study: A —radar-sized domain, B-arraysized domain, and $\mathrm{C}$-basin-sized domain. The contours are the regressed CWV values $\left(\mathrm{mm} \mathrm{mm}^{-1} \mathrm{~h}^{-1}\right)$ with MJO-filtered precipitation anomalies in the equatorial Indian Ocean $\left(2^{\circ} \mathrm{N}-2^{\circ} \mathrm{S}, 70^{\circ}-75^{\circ} \mathrm{E}\right)$; the contours are stippled to show the $95 \%$ significance level. The $\mathrm{CWV}$ values are ERA-I data between 2011 and 2013; the MJO-filtered anomalies are from the TRMM 3B42 dataset. Note that the units can be interpreted as the CWV anomalies (mm) associated with a $1 \mathrm{~mm} \mathrm{~h}^{-1} \mathrm{MJO}$-filtered rainfall anomaly averaged over the $2^{\circ} \mathrm{N}-2^{\circ} \mathrm{S}$, $70^{\circ}-75^{\circ} \mathrm{E}$ region.

use LCT to further explore the imprints of these feedbacks. We specifically ask the follow questions:

(i) Can we find statistically convincing evidence for positive moisture-convection feedbacks in observations? What is the relevance of such evidence for the MJO?

(ii) What environments and cloud types favor these positive feedbacks?

To answer these questions, we employ moisture budget analysis, which has been extensively used in the recent past to probe the phenomenological aspects of the MJO (Kiranmayi and Maloney 2011; Andersen and Kuang 2012; Sobel et al. 2014). We focus on the tropical Indian Ocean, a region of special significance to MJO initiation and the site of extensive observations collected during the Dynamics of the Madden-Julian Oscillation (DYNAMO) field campaign (Yoneyama et al. 2013).

\section{Data and methods}

\section{a. Data}

The primary data source for this study is the ERA-Interim (ERA-I) (Dee et al. 2011) dataset (http:// apps.ecmwf.int/datasets/data/interim-full-daily/levtype $=\mathrm{pl} /$ ) produced by the European Centre for Medium-Range Weather Forecasts (ECMWF). Moisture, wind, and evaporation terms were all obtained from ERA-I at a horizontal resolution of $0.25^{\circ}$ and a 6-hourly time scale for a period of 18 years (1997-2014). The spatial scales of analysis include a radar-sized domain $\left(1.75^{\circ} \mathrm{S}-0.75^{\circ} \mathrm{N}, 71.25^{\circ}-74.25^{\circ} \mathrm{E}\right)$ roughly coincident with the range of the scanning precipitation radars stationed on Gan Island/Addu Atoll during DYNAMO, a sounding array-sized domain $\left(1.75^{\circ} \mathrm{S}-5.5^{\circ} \mathrm{N}\right.$, $\left.71.25^{\circ}-82.5^{\circ} \mathrm{E}\right)$ taken to match the size of the northern sounding array during DYNAMO, and a basin-sized domain $\left(10^{\circ} \mathrm{S}-10^{\circ} \mathrm{N}, 65^{\circ}-95^{\circ} \mathrm{E}\right)$ taken to include the entirety of the MJO's CWV anomaly during an active phase in the central Indian Ocean. These domains are shown in Fig. 1.

Observations from Gan Island during DYNAMO are utilized in the latter portion of this study. Hourly averaged precipitation and $10-\mathrm{dB} Z$ echo-top heights were obtained from the Shared Mobile Atmospheric Research and Teaching Radar (SMART-R) (DePasquale et al. 2014). The SMART-R near-surface reflectivity values were used to separate these quantities into convective and stratiform regions using an algorithm based on horizontal peakedness (Steiner et al. 1995). Concurrent measurements of moisture from Gan Island were obtained from the mergesonde product available on the ARM archive (https://www.arm. gov/data/vaps/mergesonde). These hourly averaged values of precipitation and moisture are available from 2 October 2011 to 9 February 2012. Our other source of observations from Gan is the objective analysis of large-scale forcing data, which is the output from a single-column model 
whose mass, momentum, and moisture budgets are constrained using precipitation and sounding observations from Gan and 3-hourly ECMWF analyses. The domain size of the variational analysis dataset is roughly the size of the radar-sized domain described above. The methodology used to obtain this data is described more in detail in Zhang and Lin (1997) and Zhang et al. (2001).

Tropical Rainfall Measuring Mission (TRMM) Multisatellite Precipitation Analysis (TMPA) (TRMM 3B42 product; Huffman et al. 2007; https://mirador.gsfc.nasa.gov) was filtered for tropical intraseasonal waves (Wheeler and Kiladis 1999). The rain product, originally on a 3-hourly, $0.25^{\circ}$ grid was interpolated onto a 6-hourly, $1^{\circ}$ grid before the wave filters were applied, as in Schreck et al. (2011). The filtered waves included the MJO (eastward wavenumbers 0-9 and a frequency of 20-100 days), the Kelvin wave (eastward wavenumbers 1-14, a frequency of 2.5-17 days, and equivalent depths of 5-90 m), the mixed Rossby-gravity wave (MRG; westward wavenumbers 1-10, a frequency of 3-96 days, and equivalent depths of 8-90 m), and the $n=1$ westward-propagating inertio-gravity waves (WIG; westward wavenumbers 1-15, frequency of 1.25-3 days, and equivalent depths of 12-90 m). Three years (2011-13) of this product were used to discern the influence on the moisture budget terms using regression analysis. An example is shown in Fig. 1, where the background contours are daily-averaged CWV anomalies from ERA-I regressed with the daily-averaged MJO-filtered precipitation over the equatorial Indian Ocean $\left(2^{\circ} \mathrm{N}-2^{\circ} \mathrm{S}, 70^{\circ}-75^{\circ} \mathrm{E}\right)$ for the 3 -yr time period mentioned above. As anticipated, the columnmoisture anomalies associated with the MJO span a considerable part of the equatorial Indian Ocean basin.

\section{b. The moisture budget}

The energetics of the MJO can be discerned using column-integrated MSE (e.g., Kiranmayi and Maloney 2011; Sobel et al. 2014; Inoue and Back 2015). However, CWV is central to the theories of transition to strong convection (Peters and Neelin 2006; Neelin et al. 2009) and to interpretations of the MJO as a moisture mode (Sobel and Maloney 2013; Adames and Kim 2016), and it is our variable of interest. We partition the moisture budget using the framework proposed by HME16 in which the Eulerian tendency of CWV is grouped with the column-integrated horizontal advection (HADV) to yield the LCT,

$$
\left\langle\frac{\partial q}{\partial t}\right\rangle=-\left\langle V_{h} \cdot \nabla_{h} q\right\rangle-\underbrace{\left\langle\omega \frac{\partial q}{\partial p}\right\rangle-P+E}_{\text {LCT }} .
$$

Angle brackets denote vertical integration from 1000 to $100 \mathrm{hPa}$. LCT as defined here includes moistening tendencies resulting from surface evaporation and the difference between the column-integrated vertical advection of moisture and precipitation. As explained in HME16, the use of LCT to study the moisture budget mitigates the problem of bearing the uncertainties associated with vertical velocity estimation and precipitation measurements. These uncertainties are problematic because LCT is the difference between two terms that are large in magnitude and opposite in sign. A direct calculation will therefore yield a quantity whose sign is highly sensitive to the errors in the parent terms. This indirect estimation extracts a single variable that represents the moistening and drying processes in the column, subject to the smaller uncertainties associated with the Eulerian tendency and advection terms.

When surface evaporation is removed from LCT, the remnant quantity is the difference between the columnintegrated vertical advection and precipitation, which we name $\mathrm{LCT}_{E}$. This term, similar to LCT, is indirectly estimated from the column-integrated Eulerian tendency, horizontal advection, and surface evaporation terms from ERA-I,

$$
\left\langle\frac{\partial q}{\partial t}\right\rangle+\left\langle V_{h} \cdot \nabla_{h} q\right\rangle-E=\underbrace{-\left\langle\omega \frac{\partial q}{\partial p}\right\rangle-P}_{\mathrm{LCT}_{E}} .
$$

The removal of evaporation from LCT leaves only the difference between vertical advection of moisture and precipitation. For our purposes, $\mathrm{LCT}_{E}$ is equivalent to the "column process" term (Chikira 2014; Wolding and Maloney 2015; Janiga and Zhang 2016; Wolding et al. 2016). $\mathrm{LCT}_{E}$ subsumes the effects of the dynamicthermodynamic cloud complex, which includes microphysical, turbulent, and radiative processes acting in the vertical, intertwined with circulation changes moving mass into or out of the column. The magnitude and sign of $\mathrm{LCT}_{E}$ correspond to the amount of cloud-mediated moistening or drying. The indirect computation of $\mathrm{LCT}_{E}$ will include the large residual term in the MSE budget reported in Kiranmayi and Maloney (2011), who speculated that the residual represented a moistening source possibly related to shallow convection. If this is indeed the case, then it would be appropriate to group the residual under $\mathrm{LCT}_{E}$; if not, then the existence of the residual will act as a caveat on the results of this study. Note that HME16 also used $\mathrm{LCT}_{E}$ in their analysis on the possible feedbacks with CWV, which we build upon in this study.

If positive moisture-convection feedbacks are active in reality, then positive perturbations in $\mathrm{LCT}_{E}$ should cooccur with positive perturbations in CWV. We therefore utilize $\mathrm{LCT}_{E}$ to look for signatures of positive moistureconvection feedbacks in the ERA-I dataset. Note that 

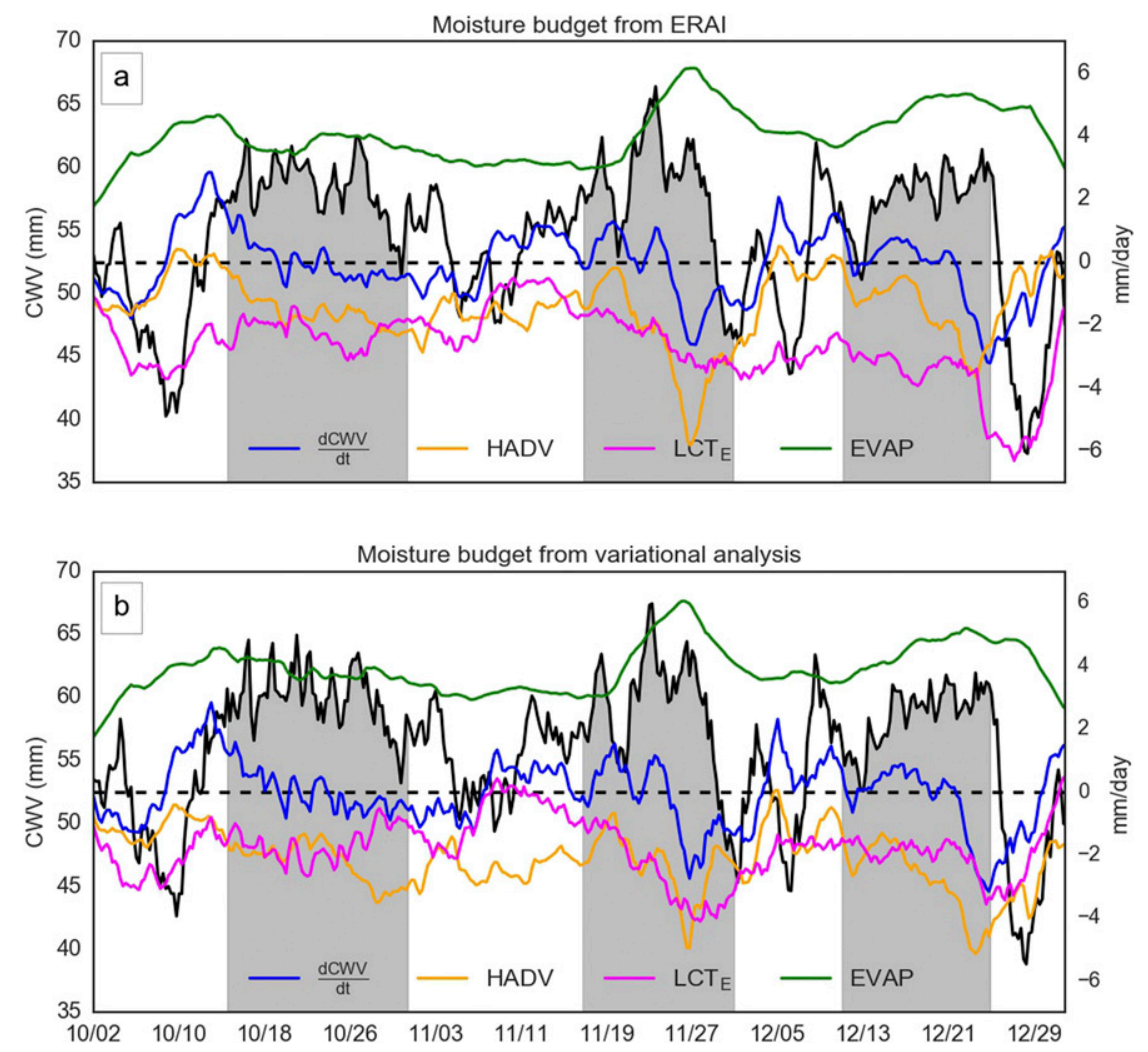

FIG. 2. Comparison of the moisture budget terms from (a) the ERA-I radar-sized domain and (b) a variational analysis dataset centered over Gan Island during the DYNAMO time period (2 Oct-31 Dec 2011). The CWV value is indicated (black line; left-hand-side axis); the moisture budget terms are also indicated (colored lines; right-hand-side axis). The three MJO events are marked as well (gray shading). All terms are smoothed with a 7-day boxcar filter.

other modes of moisture destabilization, through either surface evaporation or horizontal advection, if relevant, should also exhibit spectral signatures. We therefore proceed by first constructing the moisture budget from ERA-I.

\section{c. Validating ERA-I}

Figure 2 compares the moisture budget terms from ERA-I averaged over the radar-sized domain (Fig. 2a) with the corresponding terms from the variational analysis (Fig. 2b) for a 3-month time period during the DYNAMO field campaign. The active MJO dates (shaded) were defined as days with anomalously positive MJO-filtered precipitation as obtained from TRMM 3B42. The budget terms from ERA-I and the variational analysis show good correspondence with the moistening tendency ( $d \mathrm{CWV} / d t$; blue) and surface evaporation $(\mathrm{EVAP}=E$; green $)$ terms. There are some differences in the column-integrated HADV $\left(=-\left\langle\nabla_{h} \cdot V_{h}\right\rangle\right.$; yellow $)$ terms, which consequently lead to differences in the $\mathrm{LCT}_{E}$ (magenta) terms, particularly in the last week of December. The variational analysis moisture budget does not have a large residual, as the moisture budget is adjusted to minimize spurious residuals (Zhang et al. 2001). This difference in the partitioning of the moisture source is a possible source of the discrepancies observed between the two datasets.

Overall, the trends observed in other moisture budget analyses from DYNAMO (Sobel et al. 2014; Ruppert and Johnson 2015; HME16) are confirmed in Fig. 2. The active phase of the MJO is marked by periods of high (time filtered) CWV values (black lines $>55 \mathrm{~mm}$ ), which motivates the examination of the mechanisms that lead to and maintain this increase. The MJO events have preceding moistening sources attributable to HADV and/or $\mathrm{LCT}_{E}$. There is a marked increase in EVAP during the November MJO event (between 20 and 29 November), which corresponds to signals of air-sea coupling reported for this event (Fu et al. 2015). Strong advective drying, presumably associated with the meridional transport of dry subtropical air by the off-equatorial cyclonic gyres (Kerns and Chen 2014), ushers in the demise of the November and December MJO events, seen as sharp CWV decreases. 

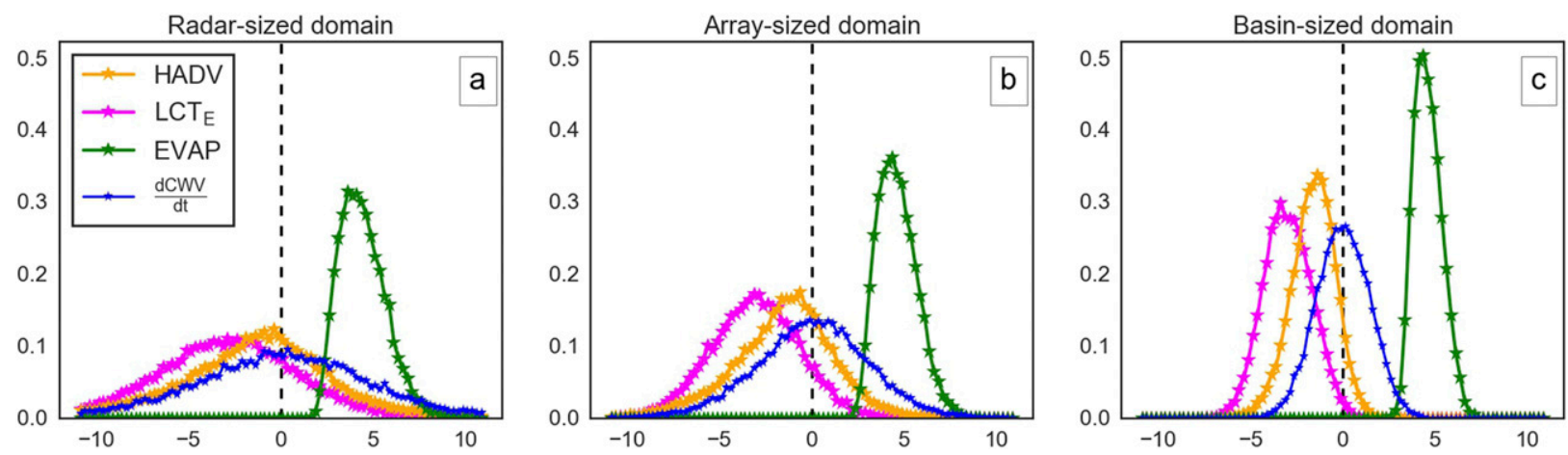

FIG. 3. The probability distribution functions of $\mathrm{LCT}_{E}$, HADV, EVAP, and CWV tendency for (a) radar-, (b) array-, and (c) basin-sized domains; $0 \mathrm{~mm} \mathrm{day}^{-1}$ is marked (vertical dashed line).

The role of EVAP as a strong, constant background source to the CWV is highlighted in Fig. 3, which presents the PDFs of $\mathrm{LCT}_{E}$, HADV, EVAP, and CWV tendency for the three domain sizes shown in Fig. 1. $\mathrm{LCT}_{E}$ and HADV are more variable (larger PDF widths) than EVAP, suggesting that these terms fluctuate-with smaller autocorrelation times-in the backdrop of persistent surface evaporation. In addition, $\mathrm{LCT}_{E}$ and HADV indicate only a few instances of an absolute moistening contribution to the CWV tendency, which itself is centered on zero moistening. The widths of the PDFs for all four terms are larger over the smaller domain (Fig. 3a) and tend to narrow with spatial averaging (Figs. 3b,c). The CWV tendency variance is the sum of the variances in the source terms$\mathrm{LCT}_{E}, \mathrm{HADV}$, and EVAP — in addition to the pairwise covariance between each of the source terms. The variability in CWV tendency is largely driven by variability in $\mathrm{LCT}_{E}$ and HADV, though the relative contribution to the variability in CWV tendency from EVAP increases as the domain size increases.

\section{Spectral analysis}

In this section we present the results of Fourier spectral analysis on the moisture budget terms from the 18-yr time series over the three domains in Fig. 1. The spatially averaged time series of each budget term in each domain was subject to the conventional preprocessing techniques used in past studies (e.g., Wheeler and Kiladis 1999; Hendon and Wheeler 2008; Yasunaga and Mapes 2012b). The 6-hourly data were daily averaged, and the annual mean and the first three harmonics of the annual cycle were removed from the dataset. The time series was then divided into 96-day segments with 30 overlapping days. Each segment was tapered using a Hann window and then Fourier transformed to obtain the power spectrum. The power spectra of all segments were averaged to produce a representative spectrum for the entire time series on the intraseasonal time scale. The averaged power spectrum is then smoothed using a 1-2-1 filter to increase the degrees of freedom, which can then be computed as 2 (amplitude and phase) $\times$ 18 (years) $\times 365$ (days) $\times 3$ (smoothing by a $1-2-1$ filter $) /$ 96 (days per segment) $\sim 410$.

Figure 4 presents the $\mathrm{LCT}_{E}$ power spectra for the three different areal averages. The dashed and dotteddashed lines are the $99 \%$ and the $95 \%$ significance levels, respectively, and were computed using the $F$ test for statistical significance of the spectral peak above an assumed red noise background with the same degrees of freedom. The spectral power has also been normalized by the magnitude of the Hann window. $\mathrm{LCT}_{E}$ displays significant spectral peaks, the first of which is prominent around 32-48 days. There are also bands of spectral peaks around 2 and 4 days. The low-frequency (32-48 days) peaks strengthen and the high-frequency ( 2 days) peaks weaken with larger averaging domains. Since the domains considered here are in the deep tropics $\left(<10^{\circ}\right.$ about the equator), equatorial Rossby waves are not expected to contribute strongly to the low-frequency signal $\mathrm{LCT}_{E}$ in Fig. 4. We can therefore conjecture that the signals in Fig. 4 correspond to the low-wavenumber MJO and the high-wavenumber inertio-gravity wave (Takayabu 1994; Takayabu et al. 1996; Haertel and Kiladis 2004), respectively. Inertiogravity waves in the equatorial regions are mostly westward propagating (Liu et al. 2011).

The 4-day spectral peaks could correspond to Kelvin waves or MRGs. Decomposing the $\mathrm{LCT}_{E}$ signals in the basin-sized domain into symmetric and antisymmetric signals shows more prominent spectral peaks in this frequency band in the antisymmetric component (not shown). This suggests that they are likely MRGs, even though Kelvin waves do have a strong HADV component (see section 4). 

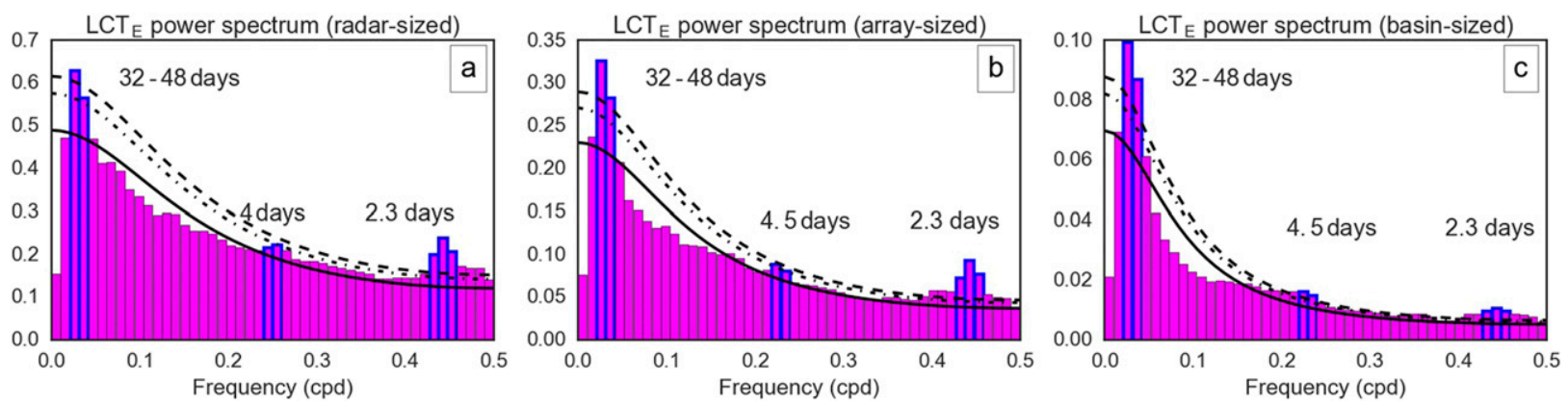

FIG. 4. The power spectra for daily-averaged $\mathrm{LCT}_{E}$ data spatially averaged over (a) radar-, (b) array-, and (c) basin-sized domains. The data are from 18 years (1997-2014) of ERA-I. The red noise curve (solid black) is computed from the autocorrelation time of the data. The 95\% (dotted-dashed) and 99\% (dashed) significance levels are computed from an $F$ test. The significant peaks near the low- and highfrequency ranges are highlighted (blue lines).

Figure 4 demonstrates that $\mathrm{LCT}_{E}$ fluctuates on the time scale of at least two prominent tropical modes of variability and confirms that the MJO and the WIG, both with prominent spectral signatures associated with convection (Wheeler and Kiladis 1999), strongly modulate the column process. While moisture convergence and precipitation can be individually expected to vary on these time scales, there is no a priori reason for the residual term (plus errors) to vary on the same time scales. Since $\mathrm{LCT}_{E}$ is inferred from the rest of the terms of the moisture budget [Eq. (1)], it is instructive to examine the spectral properties of the other terms on all three domains (see Fig. A1 in the appendix). Some of the spectral peaks in Fig. 4 have counterparts in the other terms of the moisture budget, but the 48and 2-day peaks do not, suggesting that these peaks are unique to the moist processes in the column.

When analyzing two time series, the magnitude of the coherence-squared $\left(\mathrm{coh}^{2}\right)$ statistic is useful in discerning the strength of the linear relationship as a function of frequency. The $\operatorname{coh}^{2}$ statistic between two time series, $x(t)$ and $y(t)$, is defined as

$$
\operatorname{coh}^{2}(\omega)=\frac{\left|\bar{F}_{x y}(\omega)\right|^{2}}{\bar{F}_{x x}(\omega) \bar{F}_{y y}(\omega)},
$$

where $\omega$ is the frequency; and $F_{x y}(\omega)=F_{x}(\omega) F_{y}^{*}(\omega)$, the cross-spectrum between $x(t)$ and $y(t)$, is a product of the Fourier transform $F$ and the complex conjugate of the Fourier transform $F^{*}$. Note that the denominator in Eq. (3) is the product of the power spectra of $x(t)$ and $y(t)$. The overbar indicates averaging over all the 96-day subensembles of the 18 -yr time series, followed by $1-2-1$ smoothing. The phase angle in radians is the argument of the complex quantity $\bar{F}_{x y}(\omega)$.

We identify spectral signatures of moisture-convection feedbacks as peak $\operatorname{coh}^{2}$ values between $\mathrm{LCT}_{E}$ and CWV with an in-phase relationship signifying a positive feedback.
The left column in Fig. 5 shows the $\operatorname{coh}^{2}$ between CWV and the two source terms, $\mathrm{LCT}_{E}$ and HADV. The right column of Fig. 5 shows the corresponding phase information.

In all three domains, there are $\operatorname{coh}^{2}$ peaks at low frequencies (32-96 days) with maximum coherence at 48 days, and $\operatorname{coh}^{2}$ increases from less than $\sim 0.4$ to $\sim 0.55$ as the domain size increases (Figs. 5a,c,e). LCT $_{\mathrm{E}}$ leads CWV by about $20^{\circ}$ ( $\sim 2$ days) at the low-frequency time scale (Figs. 5b,d,f), with the small angle signifying that these terms are nearly in phase. This is construed as evidence of the presence of strong positive moistureconvection feedbacks that significantly peak at the MJO time scale. HADV has large $\operatorname{coh}^{2}(>0.5)$ with $\mathrm{CWV}$ at the same time scale coincident with a $\sim 130^{\circ}-140^{\circ}$ phase angle. This suggests that decreases in HADV lag increase in $\mathrm{CWV}$ by $40^{\circ}-50^{\circ}$ at this time scale. The physical interpretation is that at low frequencies, decreases in HADV act to damp increases in CWV. This relationship between HADV and CWV would be consistent with the role of the advective drying process in the demise of MJO events. The large $\operatorname{coh}^{2}$ values between HADV and $\mathrm{LCT}_{E}$ indicate that moistening on the low-frequency time scale is still subject to variations in HADV, with Fig. 5e indicating that about half of the moistening and drying variations in the $\mathrm{CWV}$ on the low-frequency time scale are associated with moisture-convection feedbacks, while the other half are explained by HADV.

Figure 5 also shows that while $\operatorname{coh}^{2}$ between $\mathrm{LCT}_{E}$ and $\mathrm{CWV}$ is highest for the 48-day time scale, frequencies beyond 0.1 cycles per day (cpd) have reduced $\operatorname{coh}^{2}$ values (roughly half of $\operatorname{coh}^{2}$ at the low-frequency time scale), though there are patches of even smaller $\operatorname{coh}^{2}$ at the very highest frequencies $(>0.45)$. The value of $\operatorname{coh}^{2}$ between HADV and CWV, on the other hand, generally increases away from the low-frequency time scale, remaining large ( $>0.4)$ for synoptic time scales (3-10 days) in all three domains (Figs. 5a,c,e). Synoptic-scale fluctuations in $\mathrm{CWV}$ are therefore largely controlled by 

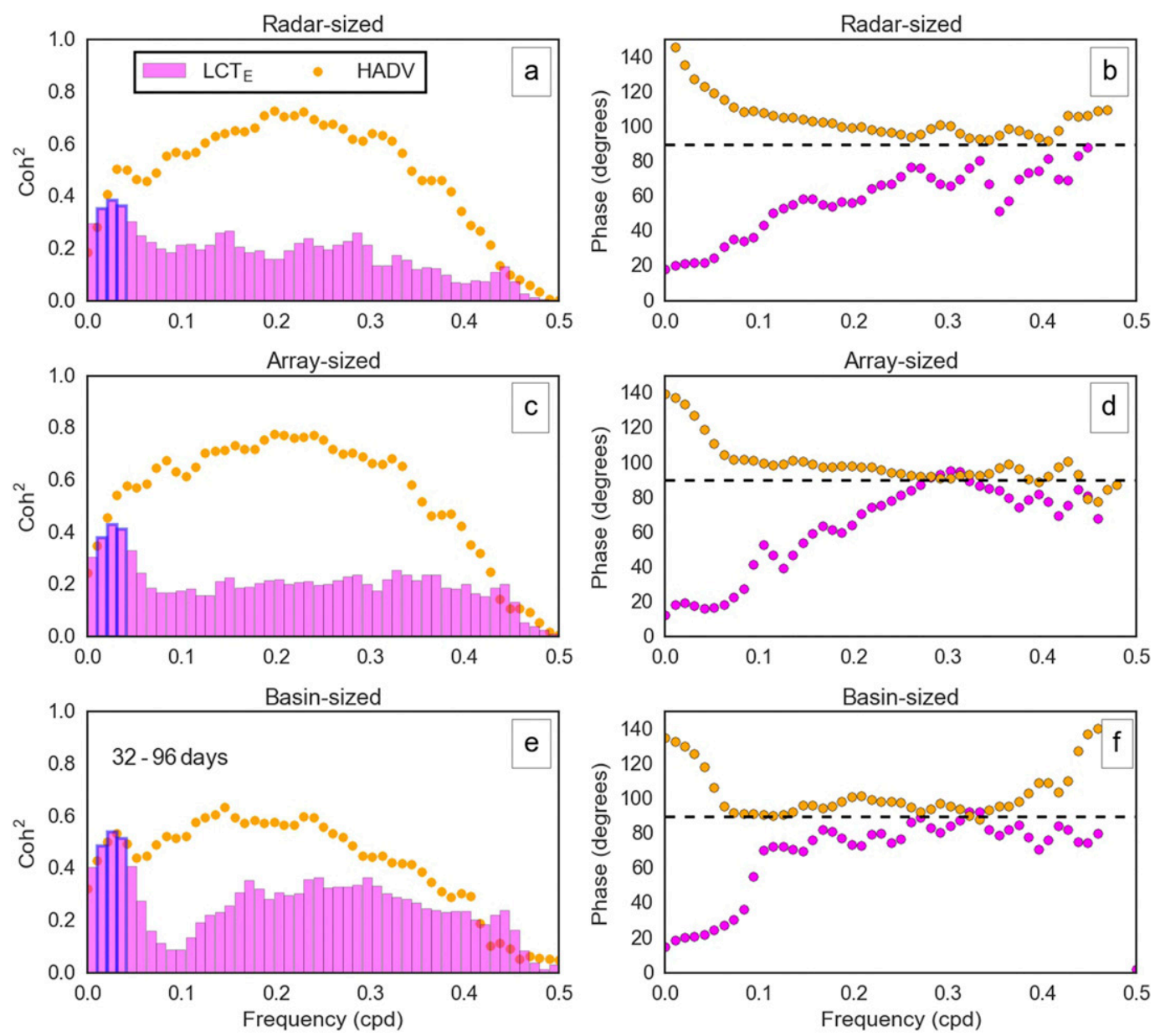

FIG. 5. (a),(c),(e) The $\operatorname{coh}^{2}$ statistic between CWV and the two terms of the moisture budget: $\mathrm{LCT}_{E}$ (magenta bars) and HADV (orange dots). (b),(d),(f) The corresponding phase difference for different domains: (a),(b) radar-, (c),(d) array-, and (e),(f) basin-sized domains. The moisture budget terms are from ERA-I for an 18-yr time period (1997-2014). The $90^{\circ}$ phase angle is indicated in (b), (d), and (f) (dashed line).

HADV. The phase angles for both HADV and $\mathrm{LCT}_{E}$ with CWV converge toward $90^{\circ}$ as the frequency increases (Figs. 5b,d,f), with the rate of convergence fastest in the largest domain size. This suggests that at the higher frequencies, HADV and $\mathrm{LCT}_{E}$ contribute more to the propagation of $\mathrm{CWV}$ variations (the quadrature component) than their maintenance (the in-phase component).

The contribution of $\mathrm{LCT}_{E}$ (HADV) increases (decreases) with the size of the domain (cf. Figs. 5c,e) for all frequencies, suggesting that scaling involving the magnitude of the horizontal velocity and domain size might control the respective contributions of HADV and $\mathrm{LCT}_{E}$ to $\mathrm{CWV}$ variations. It is notable that at high frequencies $(>0.4 \mathrm{cpd})$, the $\mathrm{coh}^{2}$ values of both $\mathrm{LCT}_{E}$ and HADV reduce considerably. This might be because of increased noise in the moisture budget and CWV terms at these frequencies, such that only a small part of the spectral covariance between two noisy terms explains the total variance in each. Overall, Fig. 5 suggests that positive moisture-convection feedbacks show statistically significant signals over the tropical Indian Ocean on the low-frequency time scales, with stronger signals on larger domains.

\section{Wave-filtered moisture budget}

Given the evidence for the role of positive moistureconvection feedbacks on low-frequency time scales from reanalysis data, we now ask if these feedbacks are associated with a particular wave type. The analysis in this section is similar to that from Inoue and Back (2015, see their Fig. 2) but for wavenumber-filtered anomalies in addition to frequency-filtered anomalies. We use the TRMM 3B42 dataset filtered for the wavenumber and frequency of tropical waves commonly found over the 

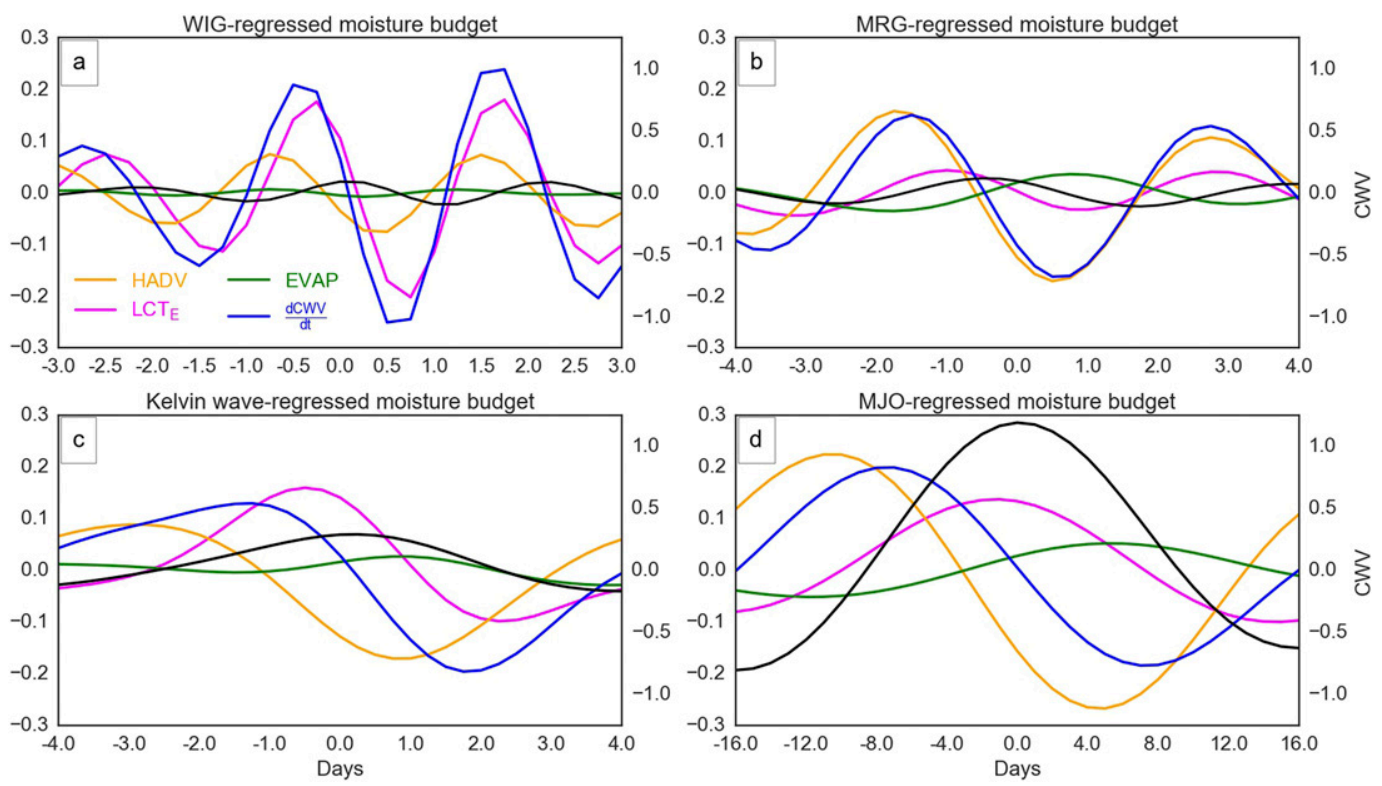

FIG. 6. ERA-I moisture budget terms regressed against TRMM 3B42 filtered precipitation anomalies, averaged over the basin-sized domain. The regression coefficients are presented for four different tropical waves: (a) WIG, (b) MRG, (c) Kelvin wave, and (d) MJO. The CWV (solid black; $\mathrm{mm} \mathrm{mm}^{-1}$ day $^{-1}$; right axis) and the other source terms (colored curves; unitless; left axis) are indicated. The CWV units signify the scale of the response associated with a $1 \mathrm{~mm}$ day $^{-1}$ wave-filtered rainfall anomaly.

equatorial Indian Ocean: the MJO, Kelvin wave, WIG, and MRG. The wave-filtered precipitation is then regressed against each term of the moisture budget averaged over the basin-sized domain and the resulting lagged regression coefficients are presented in Fig. 6. The lag-regressed CWV signals are also shown in black.

The broad patterns observed in Fig. 5 are confirmed in Fig. 6. The high-frequency WIG (Fig. 6a) has a CWV tendency (blue) nearly in phase with $\mathrm{LCT}_{E}$ (magenta). The magnitudes of the HADV variations (peak values $\sim 0.07$ ) are smaller than the $\mathrm{LCT}_{E}$ variations (peak values $\sim 0.18$ ), with CWV (black) and EVAP (green) showing even smaller variations. For MRG, $\operatorname{HADV}\left(\mathrm{LCT}_{E}\right)$ is nearly in phase with (lags) CWV tendency anomalies (Fig. 6b). The magnitudes of the variations in CWV tendency are comparable to HADV $(\sim 0.15)$, with $\mathrm{LCT}_{E}$ (0.04) and EVAP (0.03) serving only as minor contributors to the CWV tendency. These differences between MRG and WIG-particularly in their HADV and $\mathrm{LCT}_{\mathrm{E}}$ terms - underscore the rotational and divergent categorization of equatorial waves (Yasunaga and Mapes 2012a,b); the major HADV variations in the MRG are presumably meridional in origin. For the high-frequency MRG, $\mathrm{HADV}$ is more coherent with CWV tendency than $\mathrm{LCT}_{E}$, in contrast to the gross statistics for the high-frequency range in Fig. 5e, implying that the spectral properties of HADV and $\mathrm{LCT}_{E}$ can vary with the wave type being studied. Figure 6 also confirms the increasing impact of
HADV in the moisture budget with lengthening time scales, as demonstrated by Inoue and Back (2015). Given the differences between MRG and WIG, however, we will cautiously conclude that the impact of HADV is both scale and phenomena dependent.

The moisture budget of the Kelvin wave (Fig. 6c) shows a phase separation between HADV, CWV tendency, and $\mathrm{LCT}_{E}$, with HADV slightly leading and $\mathrm{LCT}_{E}$ slightly lagging the CWV tendency. The EVAP variation (0.03) is still smaller than the other terms, but the variations in HADV (0.09) and $\operatorname{LCT}_{E}$ (0.16) are more comparable. Even though the Kelvin wave is traditionally thought of as a more divergent wave-as seen in its strong $\mathrm{LCT}_{E}$ peakFig. $6 c$ suggests that HADV might also have a role to play in Kelvin wave dynamics. One straightforward explanation for the role of HADV in Kelvin wave dynamics is that strong advective moistening in the equatorial region could bring about widespread convection, which in turn can excite Kelvin waves through equatorial wave dynamics (Gill 1980). It is also possible that the HADV signature in Kelvin waves is a reflection of the nonlinear interactions between different wave types or an artifact of imperfections in the wave filter. The interaction between HADV and Kelvin wave dynamics merits future investigation, but it is beyond the scope of this study.

The Kelvin wave CWV perturbation (about $0.25 \mathrm{~mm} \mathrm{~mm}^{-1} \mathrm{day}^{-1}$ of filtered rainfall anomaly) is much larger than the perturbations in either WIG or 
the MRG. $\mathrm{LCT}_{E}$ and CWV are also more in phase, but the $\mathrm{LCT}_{E}$ anomalies seem to decrease faster than CWV anomalies can increase, precluding positive moistureconvection feedbacks. The reason for this $\mathrm{LCT}_{E}-\mathrm{CWV}$ relationship is probably attributable to Kelvin wave dynamics: the passage of the negative phase of the Kelvin wave with subsiding motions can show up as a rapid decrease in $\mathrm{LCT}_{E}$. It is also possible that the extensive stratiform rain that occurs in the cold phase of the wave (Mapes 2000; Straub and Kiladis 2003) may also contribute to this premature decrease in $\mathrm{LCT}_{E}$. To ensure that the Kelvin wave filter did not also include the signals of the $n=0$ eastward-propagating inertio-gravity wave, we used only equatorially symmetric signals in the basinsized domain to reconstruct Fig. 6c. This exercise did not show any noticeable difference (not shown).

The moisture budget of the MJO (Fig. 6d) shows some well-known properties reported in other budget studies. HADV has an appreciable in-phase component with CWV tendency-indicative of propagation-while $\mathrm{LCT}_{E}$ lags the CWV tendency. The perturbation values of HADV (0.2) and $\operatorname{LCT}_{E}(0.13)$ are also sizeable. More relevant to the thesis of this study, $\mathrm{LCT}_{E}$ and CWV are now nearly in phase, with CWV perturbations closer to $1 \mathrm{~mm} \mathrm{~mm}^{-1} \mathrm{day}^{-1}$, an order of magnitude larger than the corresponding perturbations in the Kelvin wave, without even considering magnitude differences in their filtered rainfall anomalies. Therefore, Fig. $6 \mathrm{~d}$ confirms that the low-frequency $\mathrm{coh}^{2}$ peaks in Fig. 5 are associated with the MJO. EVAP again shows only negligible variations (0.05), though they are slightly higher than the corresponding variations in the WIGs, MRGs, and Kelvin waves. The differences in the CWV perturbations associated with the MJO and the Kelvin wave suggest a possible way to diagnose robust differences between the two wave types, which may not always be clearly distinguished (Roundy 2008).

A similar regression analysis as in Fig. 6 for equatorial Rossby waves yielded a weaker moisture budget signal with smaller regression coefficients (not shown), suggesting that moisture-convection feedbacks are more important to MJO CWV dynamics than those of the other convectively coupled equatorial waves.

Figures 5 and 6 together suggest that increases in $\mathrm{LCT}_{E}$ drive increases in CWV. On short time scales, $\mathrm{LCT}_{E}$ increases lead CWV increases. However, the CWV response time is too long when compared to the time scale of $\mathrm{LCT}_{E}$ variation, such that the $\mathrm{LCT}_{E}$ negative phase damps increases in CWV. On longer time scales-with the CWV response time shorter than the $\mathrm{LCT}_{E}$ time scale-increases in $\mathrm{LCT}_{E}$ appear to be augmented by increases in CWV. The CWV response time to increases in $\mathrm{LCT}_{E}$ might therefore help explain the time-scale dependence of moisture-convection feedbacks. It is worth noting that this mechanism is similar to that of moist convective damping (Emanuel et al. 1994; Yu and Neelin 1994), which explains how a finite convective adjustment time scale can selectively damp high-frequency disturbances.

\section{The role of the cloud population}

\section{a. Moving correlation analysis}

The reconstruction of the moisture budget terms from TRMM for specific wave types in Fig. 6 corroborates the patterns seen from the spectral analysis in Fig. 5. Moisture-convective feedbacks play an important role in moistening during the $\mathrm{MJO}$, but the conditions that mediate these feedbacks still require study. This section is an investigation into the role of the environment in facilitating these moisture-convection feedbacks. The grid-scale CWV is a proxy for buoyancy over the tropical oceans (Holloway and Neelin 2009; Schiro et al. 2016) and consequently an indicator of the stages of the cloud ensemble life cycle (Masunaga 2012; Ahmed and Schumacher 2015, 2017). The weak tropospheric temperature fluctuations in the tropics (Sobel et al. 2001) leave $\mathrm{CWV}$ as the primary thermodynamic variable controlling moist processes in the tropics. We therefore ask what CWV values are able to support moistureconvection feedbacks from which we deduce the role of the cloud population.

For this analysis we use a moving correlation analysis between $\mathrm{LCT}_{E}$ and $\mathrm{CWV}$ on different domains-radar, array, and basin sized. Time intervals with moistureconvection feedbacks are identified by high correlation coefficients between $\mathrm{LCT}_{E}$ and CWV. An additional constraint of a positive mean CWV tendency during the window signifies moisture-convection feedbacks that resulted in net moistening.

We first briefly elaborate on the method of moving correlation analysis and associated caveats before presenting the results. Moving correlation analysis has been used in studies analyzing interannual variations in the relationship between two climate signals (Gershunov et al. 2001; Slonosky et al. 2001; Polyakova et al. 2006). However, there exists the danger of overinterpreting the values of correlation coefficients computed this way, since any two stochastically varying time series with an overall correlation will exhibit periods of large correlation (e.g., Gershunov et al. 2001). To estimate the significance of the moving correlation coefficient within the sliding window, we utilized a Monte Carlo simulation. We generated 5000 pairs of white noise time series with the caveat that the overall correlation coefficient between these synthetically generated pairs was the same 
as that between the two time series being analyzed. The 6-hourly time series were subject to a sliding window with a length of 51 time steps ( $\sim 12$ days) in which the Pearson's correlation coefficient was computed. The maximum values of the 99th percentile of the absolute values of the correlation coefficient between the pairs of synthetic time series were between 0.53 and 0.58 for each of the domains. These values were used to discern windows with a significant correlation between $\mathrm{LCT}_{E}$ and CWV. An additional constraint of a positive mean CWV tendency during the window was also imposed to identify only moistening periods.

These points were then used to generate population statistics for the three domain sizes (Fig. 7), where the conditional PDF of the CWV values during periods of enhanced association between $\mathrm{CWV}$ and $\mathrm{LCT}_{E}$ is shown using red curves. The green curves are the PDFs of the overall CWV values. The CWV PDF in each domain shows a distinct peak in the distribution. This peak in the CWV distribution separates a long tail for drier values, which is shaped by slow moistening, and a short tail for moister values, which is shaped by rapid drying at the onset of strong precipitation (Neelin et al. 2009). We will hereafter refer to this peak as the climatological mean of the CWV distribution, or the modal value of CWV (in the sense of the most frequent value).

The blue stars indicate the percentage of the total samples in each bin that show a period of enhanced correlation between $\mathrm{LCT}_{E}$ and $\mathrm{CWV}$ and have positive mean CWV tendency. The underlying distributions used to construct each of the two PDFs in each panel of Fig. 7 were different at the $99 \%$ significance level, as computed using a two-sample Kolmogorov-Smirnov test.

The incidence of moisture-convection feedbacksindicated by the blue stars in Fig. 7-decreases with increasing CWV, with few instances above the climatological mean of the CWV distribution, in all three domains. The decrease in moisture-convection feedbacks at high CWV values can also be seen from Figs. 10 and 11 of HME16, where their LCT (and $\mathrm{LCT}_{E}$ ) values do not change substantially with CWV at high CWV values. Since CWV is tied to cloud morphology, it appears that the cloud population at low CWV values is more effective in moistening the column. This implies that the climatological mean in the CWV PDF is shaped, at least partly, by the moistureconvection feedbacks in drier environments. In other words, the long tail in the climatological CWV PDF is attributable to the moistening effect of the cloud population.

\section{b. Cloud-top height composites from DYNAMO and the slow shallow-to-deep transition}

Thus far, it appears that positive moisture-convection feedbacks are prominent at the low-frequency time
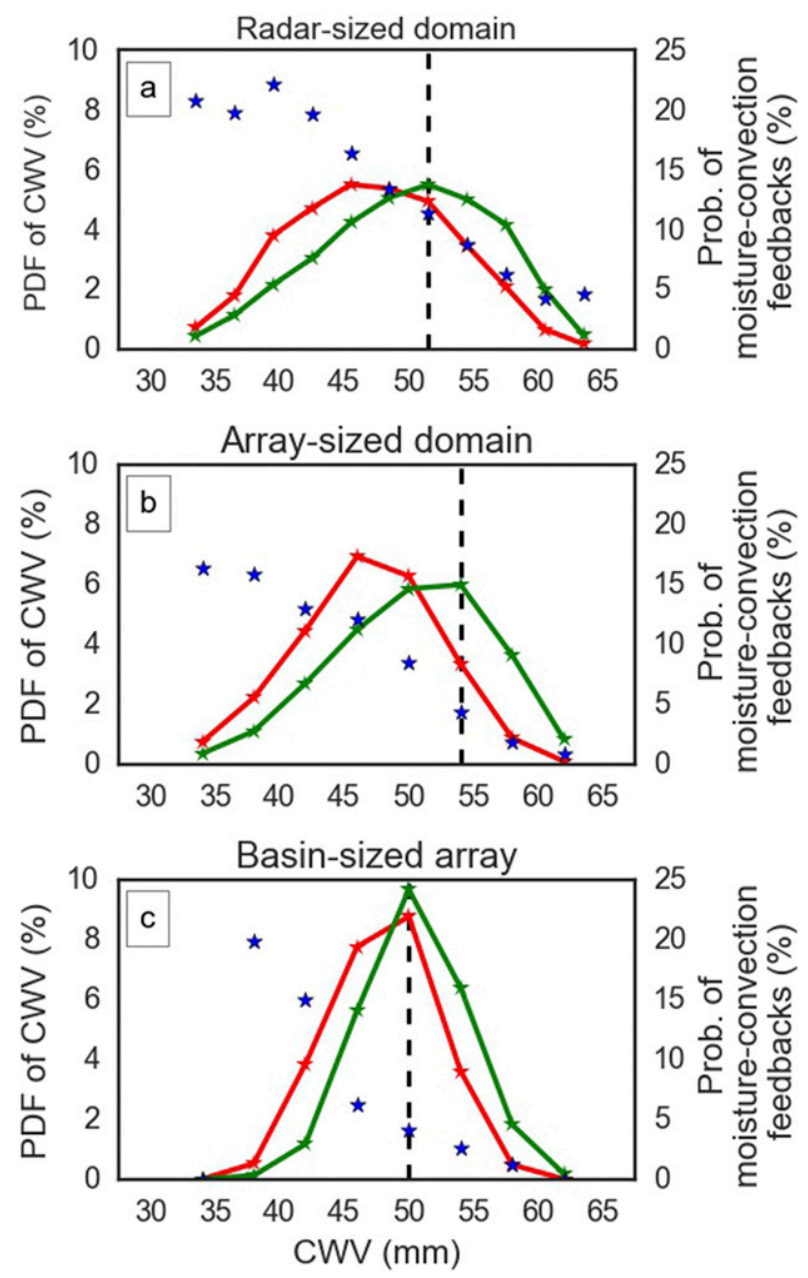

FIG. 7. The probability distribution function of two distributions: a population that represents $\mathrm{CWV}$ values from periods with positive correlation between CWV and $\mathrm{LCT}_{E}$ and the mean moistening tendency (red) and the total CWV population (green; mode is indicated by the dashed line) for (a) radar-, (b) array-, and (c) basin-sized domains. The percentage of points in each CWV bin that are found in an environment with positive moisture-convection feedbacks is also shown (blue stars; right axis). These periods are identified using a moving correlation analysis (see text for details).

scale, in slightly to moderately moist environments. Since these processes are linked to the cloud ensemble, we ask the following question: What is the morphology of the cloud ensemble that supports these feedbacks in low to moderately moist environments? To answer this question, we take advantage of the concurrent cloud and humidity measurements collected during DYNAMO. Figure 8 shows the PDF of the SMART-R hourly $10-\mathrm{dB} Z$ convective echo-top height binned by mergesonde ARM water vapor values for a 4-month time period. Figure 8a shows that $\mathrm{CWV}$ values below the climatological mean on the radar-scale domain are predominantly associated with shallow and congestus clouds. There appear 

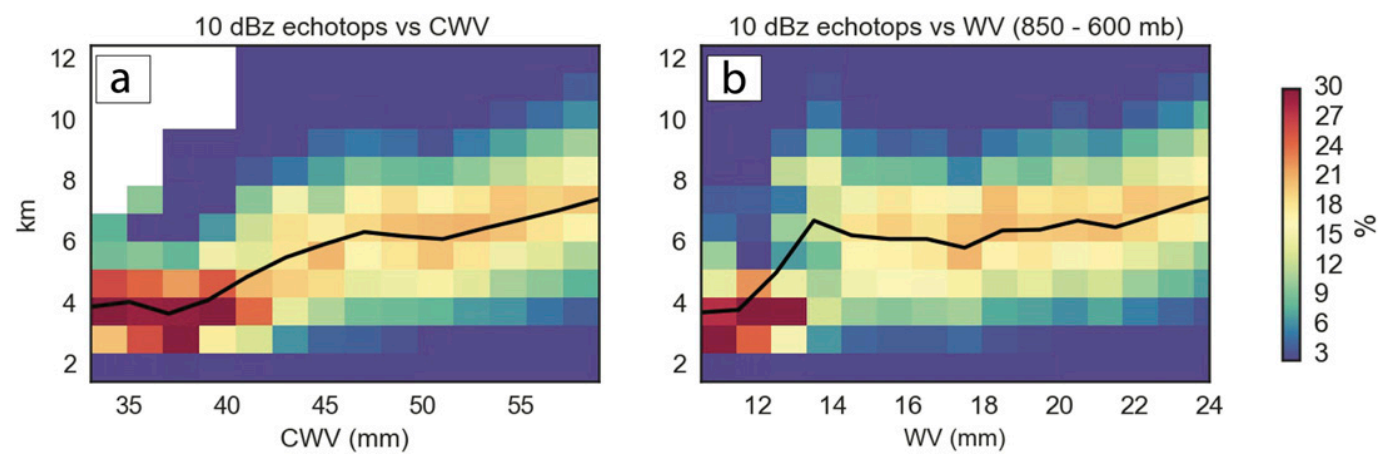

FIG. 8. The relationship between cloud population and CWV as seen from 10-dBZ convective echo-height distribution conditioned on (a) CWV and (b) water vapor integrated between 600 and $850 \mathrm{hPa}$. The mean of the distribution in each bin is indicated (black line). The echo-top-height histograms are computed at 3-hourly intervals from SMART-R data from 2 Oct 2011 to 9 Feb 2012. The CWV values are obtained from the ARM mergesonde product for the same time period.

to be two thresholds in relation to cloud type: one between 35 and $40 \mathrm{~mm}$ that controls the transition from shallow convective clouds (echo tops $<4 \mathrm{~km}$ ) to congestus clouds (echo tops between 4 and $6 \mathrm{~km}$ ), and the other between 45 and $50 \mathrm{~mm}$ that controls the transition between congestus and deep convective clouds (echo tops $>6 \mathrm{~km}$ ). This stepwise transition in the convective cloud height was also reported by other observational studies (Del Genio et al. 2012; Johnson and Ciesielski 2013; Powell and Houze 2013). Figure 8 b stresses the role of the lower-tropospheric water vapor $(850-600 \mathrm{hPa})$ that controls the transition from shallow convective to congestus clouds. An increase of $2 \mathrm{~mm}$ of water vapor (i.e., from 12 to $14 \mathrm{~mm}$ ) in this layer results in a sharp change in the mean cloud-top height distribution of the ensemble. This layer does not affect the congestus-to-deep-convective transition.

What is the approximate time scale associated with the CWV changes in Fig. 8? A moistening tendency of $1 \mathrm{~mm} \mathrm{day}^{-1}$ (around the 60th percentile of CWV tendency over the radar-sized domain) yields an estimate of 15 days for the increase in CWV values from 40 to $55 \mathrm{~mm}$-about half the time period of a 30-day intraseasonal oscillation.

Overall, we can infer from Figs. 7 and 8 that the moisture-convection feedbacks that moisten the atmosphere are associated with shallow, congestus, and deep convective cloud populations. The moisture-convection mechanism leading to column moistening thus appears to be a manifestation of the gradual transition from shallow to deep convection, at least on the radar-scale domain. Beyond a CWV value of $\sim 50 \mathrm{~mm}$, there is a rapid pickup in the stratiform precipitation [see Figs. 1 and 2 in Ahmed and Schumacher (2015)]. As stated in the previous section, this gradual shallow-to-deep transition on time scales on the order of 10 days (the window used for moving correlation analysis) could help maintain the mean CWV field in the tropics.

\section{c. Factors inhibiting moisture-convection feedbacks in moist environments}

What causes the decrease in the incidence of moistureconvection feedbacks in humid environments above the climatological-mean CWV value? DYNAMO observations give us a way to the answer, albeit at short time scales. Figure 9 displays the relationship between $\mathrm{LCT}_{E}$ and CWV in the presence of heavy stratiform rain (which occurs at high CWV values; Ahmed and Schumacher 2015). Figure 9a shows the 3-hourly $\mathrm{LCT}_{E}$ values obtained from the DYNAMO variational analysis binned against 3-hourly values of stratiform rain fraction obtained from SMART-R. A stratiform rain threshold of $2.4 \mathrm{~mm}_{\text {day }}{ }^{-1}$ was used to identify these points to ensure at least moderately raining 3 -h periods. Figure 9a shows that large negative values of $\mathrm{LCT}_{E}$ are associated with higher stratiform rain fractions. The two quantities have an overall Spearman's rank correlation of -0.4 , indicative of moderate negative correlation. A similar effect of the stratiform clouds on the environment can be observed in HME16 (their Fig. 19).

Therefore, even though widespread stratiform rain is found in environments of high CWV, these clouds will not feed back positively onto the CWV field. To make this clearer, we composited the different terms of the moisture budget and the 10-dBZ convective echo-top height population around peak stratiform rain $\left(>6 \mathrm{~mm}\right.$ day $\left.{ }^{-1}\right)$. Figure 9b shows the distribution of the echo-top height conditioned on time around the peak stratiform rain. Peak stratiform rain is preceded by a transition in the convective cloud population, with an increased frequency of shallow clouds $10 \mathrm{~h}$ prior and a transition through congestus to deep convective clouds by peak hour displaying the canonical "tilted" vertical structure of convective clouds. There is a sharp decrease in the convective cloud population beyond 

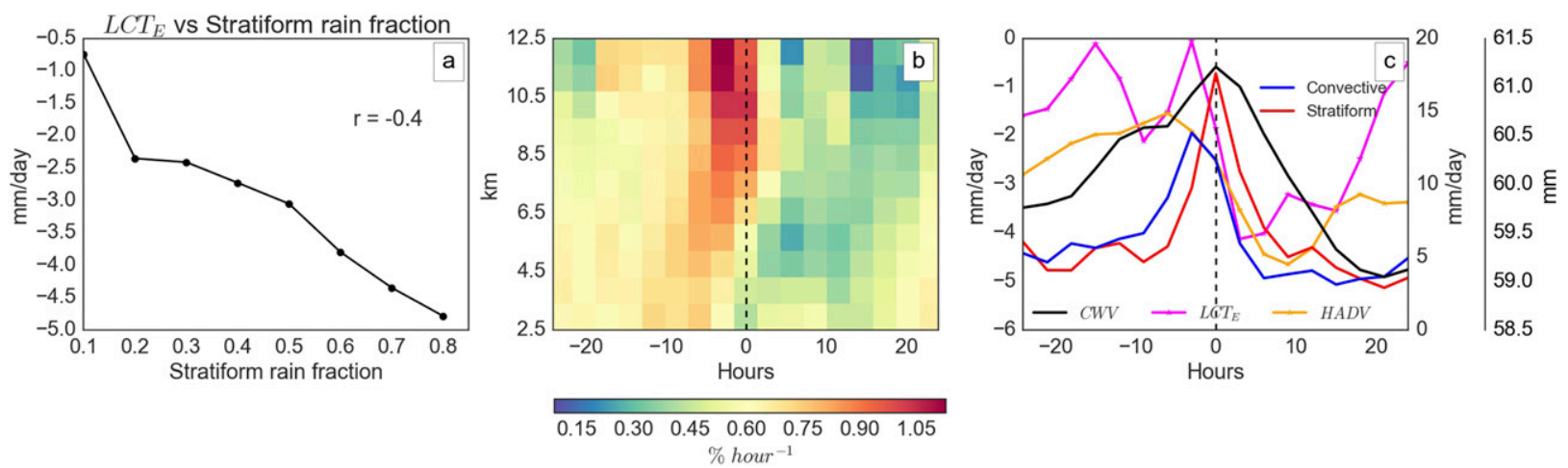

FIG. 9. (a) The relationship between 3-hourly $\mathrm{LCT}_{E}$ values from the variational analysis dataset and stratiform rain fraction from SMART-R. LCT $_{E}$ values are binned by $10 \%$ intervals of the stratiform rain fraction. The time span of the overlapping datasets is from 2 Oct to 31 Dec 2011. The Spearman's rank correlation is indicated. (b) The distribution of convective cloud-top height conditioned on the time span around the 3-hourly SMART-R stratiform rain maxima as observed by the radar. (c) The composites of the moisture budget terms (left axis) and convective and stratiform rain (inner right axis) and the CWV (solid black; outer right axis).

hour 0. Figure 9b when contrasted with Fig. 8 underscores the point that the shallow-to-deep transition can occur on different time scales. This difference in time scales of shallow-to-deep transition can be attributed to the differences in the time scales of the appropriate external forcing, as in the stretched building-block framework (Mapes et al. 2006). It is possible that preconditioning by shallow and congestus clouds may not be a factor on short time and small space scales as shown in some previous studies (Hohenegger and Stevens 2013; Kumar et al. 2014), but it could be important on longer and larger scales (Lappen and Schumacher 2014; Powell 2016).

Figure 9c shows a double peak in $\mathrm{LCT}_{E}$ (magenta). The first peak occurs $\sim 15 \mathrm{~h}$ prior to peak stratiform rain and is associated with a prominent diurnal cycle in $\mathrm{LCT}_{E}$ with peaks during the afternoons, even over the oceans (not shown). These daytime peaks in $\mathrm{LCT}_{E}$ are not always accompanied by increases in rainfall. The second $\mathrm{LCT}_{E}$ peak coincides with the maximum in convective rain (blue) and deep convective clouds (Fig. 9b) and then rapidly drops with peak stratiform rain (red) to a local minimum before recovering again. CWV (black) starts to gradually increase well before the $\mathrm{LCT}_{E}$ peak, with the increase facilitated by HADV (yellow). CWV responds to the damping from $\mathrm{LCT}_{E}$ and decreases, but its reduction can also be effected by HADV. The relationship between $\mathrm{LCT}_{E}$ and CWV is complicated by accompanying fluctuations in HADV. It is nevertheless clear that the presence of stratiform rain dynamics in very moist environments hinders further moistening - acting as a negative feedback on CWV. The composite plot in Fig. 9c should also explain the near-quadrature relationship between $\mathrm{CWV}$ and $\mathrm{LCT}_{E}$ seen for the high-frequency WIG in Fig. 6a. Therefore, on radar-scale domains, it appears as if the extensive presence of MCSs is not conducive for positive moistureconvection feedbacks.

The physical picture that emerges from the CWVprecipitation dynamics is that in environments moister than the mean CWV value, $\mathrm{LCT}_{E}$ acts to damp CWV increases at short time scales, while in environments drier than the mean $\mathrm{CWV}$ value, $\mathrm{LCT}_{E}$ acts to increase $\mathrm{CWV}$ increases at longer, near-intraseasonal time scales. These two time-scale-separated processes therefore appear to shape the CWV distribution. Note that the drying associated with extensive stratiform rain does not preclude a role for the top-heavy heating structures in the maintenance of the MJO (Deng et al. 2016) or for the influence of cold pools from stratiform downdrafts in initiating new convection; it only implies that further local moistening is inhibited by the presence of stratiform clouds.

\section{Vertical coherence structures}

The limited time and space observations from the DYNAMO campaign provide insights into the CWV$\mathrm{LCT}_{E}$ relationship at high frequencies. In an attempt to garner more information about the interaction between the cloud population and $\mathrm{LCT}_{E}$ on longer time and larger space scales, we looked at the profiles of vertical velocity (omega) from ERA-I for the same 18-yr period as the other moisture budget terms. Since $\mathrm{LCT}_{E}$ is affected by omega, the vertical shape of omega that covaries with $\mathrm{LCT}_{E}$ at different time scales might provide clues to the character of the cloud ensemble that is most effective in ushering positive moisture-convective feedbacks. To this end, we performed a $\operatorname{coh}^{2}$ analysis on the relationship between the vertical profile of omega and $\mathrm{LCT}_{E}$ for different spatial scales (Fig. 10). We also looked at the vertical $\operatorname{coh}^{2}$ structures between omega 


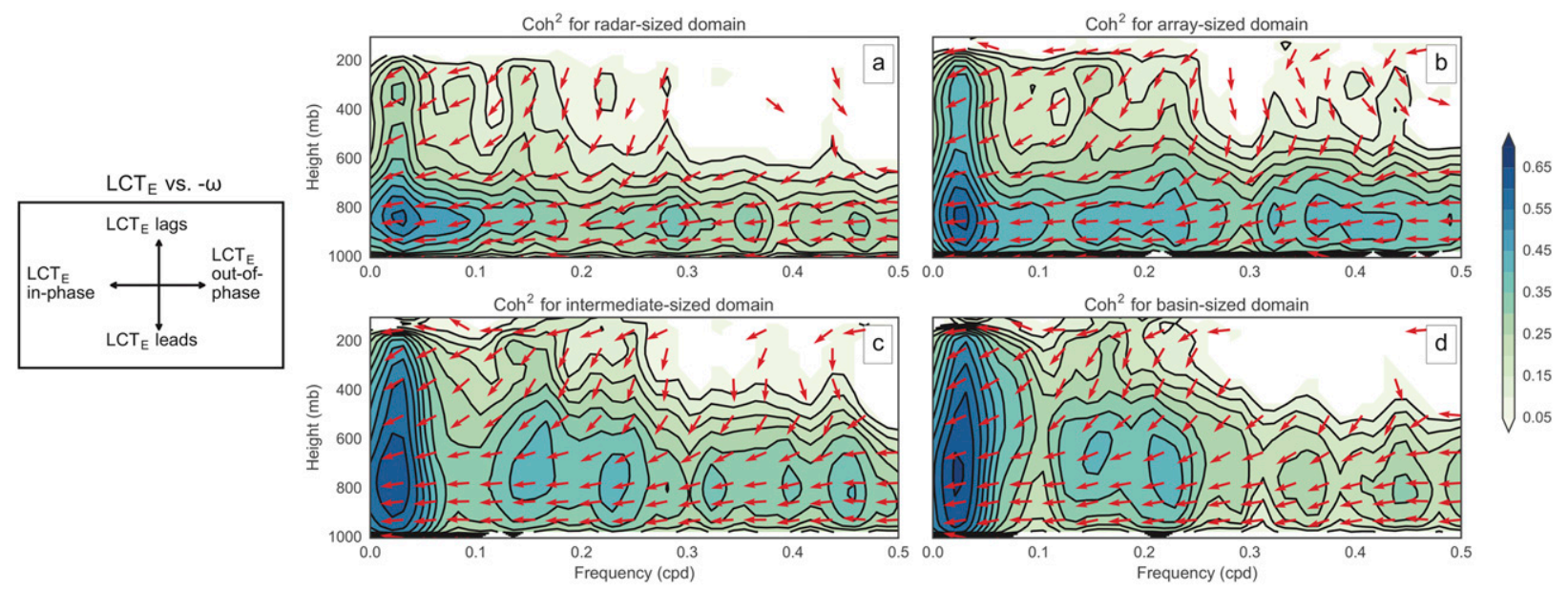

FIG. 10. (a) The $\operatorname{coh}^{2}$ statistic between $\mathrm{LCT}_{E}$ and omega for (a) radar-, (b) array-, (c) intermediate-, and (d) basin-sized domains. The phasing between the variables is indicated (red arrows). The legend interprets the phasing between $\mathrm{LCT}_{E}$ and negative omega (rising motion). For example, leftward-pointing arrows indicate that $\mathrm{LCT}_{E}$ is in phase (out of phase) with rising motion (subsidence). Omega is obtained directly from the ERA-I dataset for the same 18-yr time period (1997-2014) as LCT $_{E}$.

and HADV (Fig. 11) and omega and CWV tendency (Fig. 12) to shed light on the relationship between variations in the other moisture budget terms and the local cloud population. The omega values are daily averaged and preprocessed like the $\mathrm{LCT}_{E}$ and HADV values in section 3. To better elucidate the changing properties with domain size, we present four domains instead of the previous three. The additional domain has an area that is greater than the array-sized domain and smaller than the basin-sized domain and is termed the intermediate-sized domain. The $\operatorname{coh}^{2}$ statistic estimates the degree of the linear relationship between two variables, but it is also affected by the presence of spectral noise, thereby blurring the physical interpretation. For our purposes in this section, we assume the magnitude of noise in each frequency band is the same at every vertical level. This then allows us to interpret the vertical velocity $\operatorname{coh}^{2}$ profiles below as signatures of the cloud population varying in association with the relevant moisture budget term.

\section{a. $L C T_{E}$ versus omega}

From Figs. 4 and $6 \mathrm{~d}$ it is clear that $\mathrm{LCT}_{E}$ (or the column process) phase locks with CWV at the MJO time scale, suggesting a positive feedback between convection and moisture. Thus, the omega profile at the MJO time scale should be associated with positive moistureconvection feedbacks. Figure 10 shows that there are strong $\operatorname{coh}^{2}$ values $(>0.5)$ between low-level omega and $\mathrm{LCT}_{E}$ for all domains at low frequencies $(<0.1 \mathrm{cpd})$, with low-level peaks $(850-700 \mathrm{hPa})$ at the MJO time scale. The phase arrows suggest that anomalous rising (descending) motion is associated with anomalously positive (negative) $\mathrm{LCT}_{E}$.
The strongly bottom-heavy vertical $\operatorname{coh}^{2}$ structures at the low frequency (per 32-48 days) in Fig. 10a suggest that $\mathrm{LCT}_{E}$ strongly varies with the low-level vertical velocity at $850 \mathrm{hPa}$ but is only weakly correlated with mid- and upper-level vertical velocities. Larger domain sizes have deeper vertical structures with stronger coherence between $\mathrm{LCT}_{E}$ and negative omega spanning the entire troposphere at the low-frequency time scale, with peak coherence values shifting from 850 to $700 \mathrm{hPa}$ as the domain size increases from the radar- to basinsized domain (Figs. 10a-d).

Vertical coherence structures are not profiles of vertical velocity, but Fig. 10 does suggest that for the same precipitation amount or an equivalent quantity like the column diabatic heating $Q_{1}$ (Yanai et al. 1973), a bottomheavy omega profile will be more effective in moistening the domain via the $\mathrm{LCT}_{E}$ term than a middle- or a topheavy profile. For the same time scale, the increase in domain size also increases the vertical extent of the omega- $\mathrm{LCT}_{E}$ peak coherence, suggesting that there is an apparent spatial-scale dependency to the relationship between $\mathrm{LCT}_{E}$ and omega, with smaller domains requiring more bottom-heavy profiles for effective moistening. This interpretation of the $\mathrm{coh}^{2}$ structures in Fig. 10 supports the idea that a deep but relatively bottom-heavy vertical structure of omega facilitates moisture-convection feedbacks (e.g., Raymond et al. 2009).

Figure 10 also shows that as the frequency increases away from the MJO time scale, the $\operatorname{coh}^{2}$ values decrease but the in-phase peak coherence still peaks at the low levels, such that positive $\mathrm{LCT}_{E}$ covaries with low-level vertical motion. The upper-level phase arrows at these frequencies suggest that rising motion at these levels 


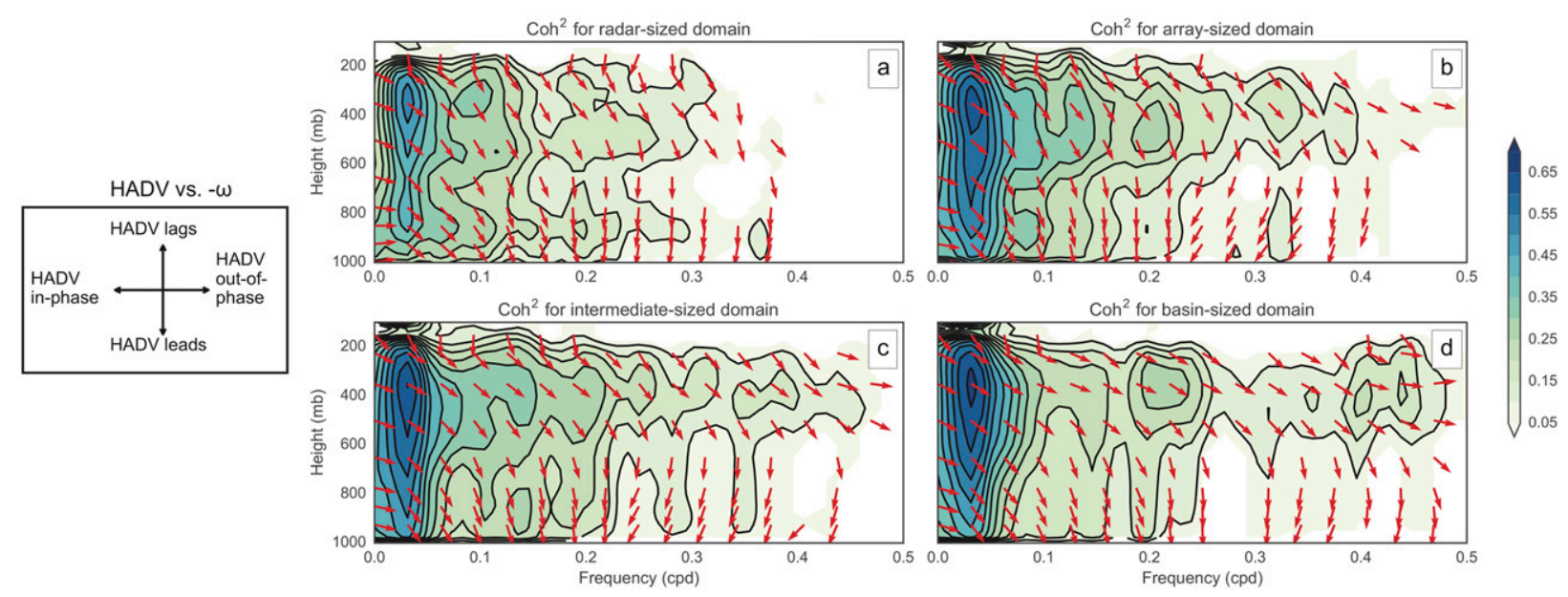

FIG. 11. As in Fig. 10, but for the relationship between HADV and omega.

lags $\mathrm{LCT}_{E}$. Overall, it is clear that low-level omega strongly covaries with $\mathrm{LCT}_{E}$ at all frequencies and domain sizes, but that the vertical extent of omega and the level of peak coherence increases as the frequency decreases.

\section{b. HADV versus omega}

Figure 11 presents the vertical $\operatorname{coh}^{2}$ structure between HADV and omega, which is deep and significantly large at the intraseasonal time scale. As was the case for $\mathrm{LCT}_{E}, \operatorname{coh}^{2}$ also strengthens and deepens with increasing domain size. In contrast to $\mathrm{LCT}_{E}$, however, the $\operatorname{coh}^{2}$ structures peak at upper levels $(\sim 300 \mathrm{hPa})$, with negative HADV perturbations lagging rising motion, with a significant out-of-phase component. The $\operatorname{coh}^{2}$ values weaken as the frequency increases, much more rapidly than for $\mathrm{LCT}_{E}$ in Fig. 10, suggesting that the HADV-omega relationship is mostly significant at low frequencies. The phase difference between HADV and upper-level omega is greater than $90^{\circ}$, implying that increases in upper-level omega are damped by HADV anomalously drying the column. A pronounced topheavy omega profile-presumably tied to a top-heavy diabatic heating profile-is the signature of a strong stratiform component (Schumacher et al. 2004; Lin et al. 2004). This $\mathrm{coh}^{2}$ between HADV and omega might simply be a spectral signature of the co-occurrence between HADV drying and increasing stratiform clouds, both of which mark the decay of an MJO event (e.g., Benedict and Randall 2007), without any causal link between the two variables. A detailed investigation of which phenomenon is responsible for the $\mathrm{coh}^{2}$ structures in Fig. 11 could be the subject of a future study.

\section{c. $C W V$ tendency versus omega}

Figure 12 presents the vertical $\operatorname{coh}^{2}$ structures for the CWV tendency with omega. As in the previous two

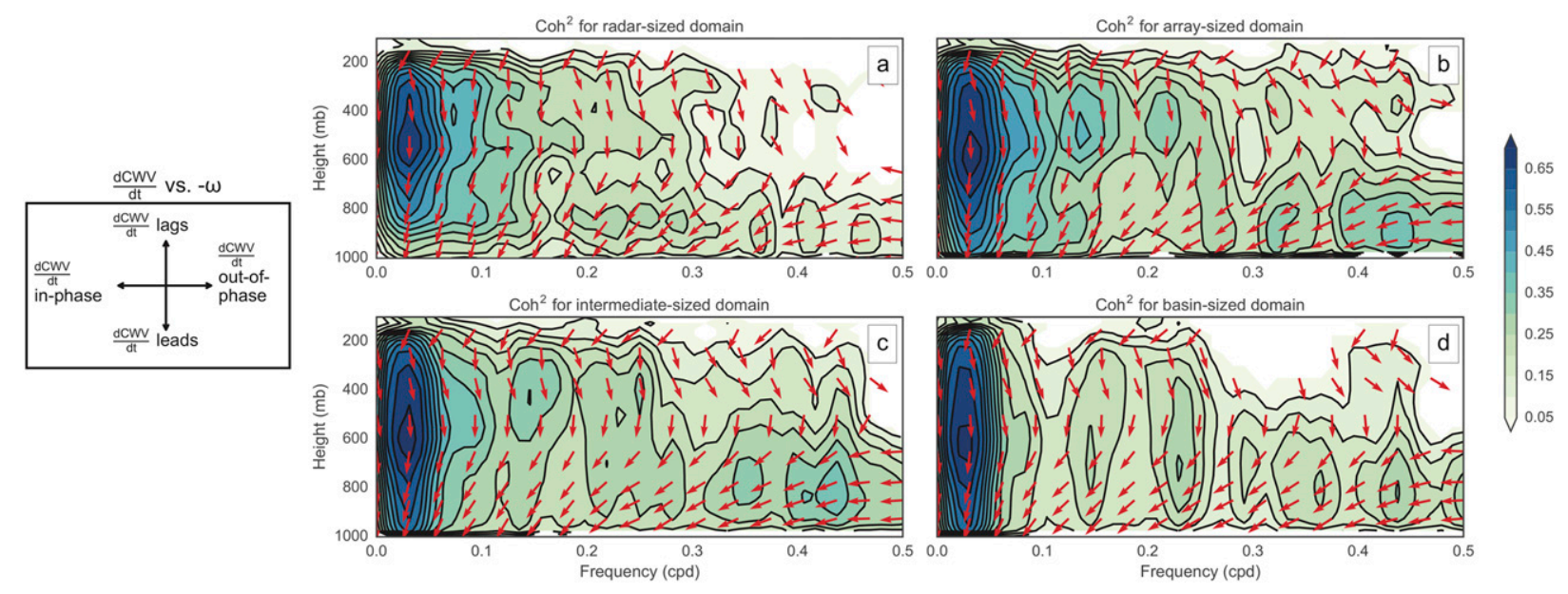

FIG. 12. As in Fig. 10, but for the relationship between CWV tendency and omega. 
figures, the $\operatorname{coh}^{2}$ structures are strong and deep for the MJO time scale, with the values spanning the entire troposphere. At the low frequencies, rising motion lags increases in CWV tendency by $90^{\circ}$ or, in other words, is in phase with CWV increases. This is consistent with the central idea of this study that moisture and convection fluctuations tend to covary at low frequencies. Unlike the $\operatorname{coh}^{2}$ structures between $\mathrm{LCT}_{E}$ and negative omega, which shows the largest variance at lower levels (Fig. 10), the $\operatorname{coh}^{2}$ structures between CWV tendency and negative omega show large $\operatorname{coh}^{2}$ signals throughout the troposphere, with peaks in the midtroposphere. Since a positive CWV tendency can be effected by any of its source terms-EVAP, HADV, or $\mathrm{LCT}_{E}-$ Fig. 12 depicts the strength of the variation between any lowfrequency moisture increase and the resulting response from the cloud population.

If the cloud response to low-frequency moisture increases took the form of higher-order vertical structures, then we would expect to find higher-order $\mathrm{coh}^{2}$ peaks in Fig. 12. However, since Fig. 12 displays a single $\operatorname{coh}^{2}$ peak in the midtroposphere, we speculate that the variance in the response of the cloud population to low-frequency moisture increases is mostly captured by the first baroclinic mode. The increasing influence of the first baroclinic mode with decreasing frequency was also documented in Inoue and Back (2015).

There are significant-albeit weaker-low-level coherent structures $\left(\mathrm{coh}^{2} \sim 0.4\right)$ for higher frequencies near $0.4 \mathrm{cpd}$ for the array- and intermediate-sized domains (Figs. 12b,c). These omega values-corresponding to peaks associated with the inertio-gravity waves-are nearly in phase with CWV tendency, consistent with the phase relationship between CWV tendency and $\mathrm{LCT}_{E}$ seen in Figs. $6 \mathrm{a}$ and 10.

Vertical $\operatorname{coh}^{2}$ structures between omega and surface evaporation were not significant (not shown), implying that variations in the surface moisture fluxes do not strongly covary with cloud morphology (Riley Dellaripa et al. 2018).

\section{Discussion and summary}

The primary objective of this study was to investigate the signatures of positive moisture-convection feedbacks and their relevance for the MJO using reanalysis data over the tropical Indian Ocean. To this end, we used $\mathrm{LCT}_{E}-$ as introduced by HME16-as our variable of choice. $\mathrm{LCT}_{E}$ incorporates the moistening processes in the column independent of advective tendencies and surface fluxes; therefore, it is an estimate of the effect of convection on CWV. The spectral signatures of moisture-convection feedback were identified using the criterion of an inphase relationship between CWV and $\mathrm{LCT}_{E}$.

On short time scales, $\mathrm{LCT}_{E}$ is in quadrature with $\mathrm{CWV}$, implying that CWV increases are removed-likely through precipitation-without any feedbacks onto the CWV perturbation. On longer, intraseasonal (32-48 days) time scales, fluctuations in $\mathrm{LCT}_{E}$ are coherent and nearly in phase with CWV, with the strength of these associations between CWV increasing for larger analysis domains, highlighting the time- and spatial-scale dependence of this feature. This spectral signature of moisture-convection feedbacks was independently confirmed using a moisture budget regressed onto filtered TRMM rainfall for different equatorial waves. Among the four different waves considered-WIG, MRG, the Kelvin wave, and the MJO-moisture increases in association with the MJO were found to be in phase with $\mathrm{LCT}_{E}$.

Our results also stress the prominent role of HADV in affecting the CWV budget. At long time scales relevant to the MJO, HADV controls almost half of the CWV variations. The efficacy of positive moisture-convection feedbacks in allowing the growth of positive moisture anomalies in the MJO is therefore implicitly subject to the fluctuations in HADV.

Moving correlation analysis suggests that environments that are moderately moist but still drier than the mean $\mathrm{CWV}$ value are more favorable for positive moisture-convection feedbacks. The implication of this result is that convection is less likely to feed back onto the environmental moisture in humid, heavily precipitating environments. The mean CWV field in the tropics is therefore likely shaped by low-frequency moisture-convection feedbacks that moisten air columns until they are moist enough to be strongly precipitating.

Ground radar observations confirm the well-known observation that the shallow and congestus convective cloud population-with bottom-heavy vertical motions-are involved in this moistening process. Composite analysis from radar and variational analysis data shows that in very humid environments, increases in stratiform rain are accompanied by rapid decreases in CWV, suggesting that stratiform clouds are a negative feedback on the local environmental moisture.

Last, vertical coherence structures were used to study the relationship between the moisture budget terms and the cloud population as a function of frequency. At low frequencies relevant to the MJO, $\mathrm{LCT}_{E}$ was in phase and strongly coherent with lowlevel rising motion and only weakly coherent with upper-level vertical velocity, confirming that bottomheavy vertical motion profiles would be more effective than other profiles (middle or top heavy) in bringing 
about moisture-convection feedbacks. This idea that positive moisture-convection feedbacks are mediated by bottom-heavy convection is consistent with previous studies (e.g., Kemball-Cook and Weare 2001; Zhang and Song 2009; Raymond et al. 2009; Kuang 2011). The slow shallow-to-deep transition (Del Genio et al. 2012; Powell and Houze 2015) that precedes the MJO active phase is the primary part of the moistureconvection feedback mechanism that increases the CWV anomalies.

The coherence between $\mathrm{LCT}_{E}$ and vertical velocity was subject to the domain size under consideration. In larger domains $\mathrm{LCT}_{E}$ is coherent with rising motion through a deeper tropospheric layer, while $\mathrm{LCT}_{E}$ in smaller domains is coherent with rising motion in a shallow layer near the low levels $(850 \mathrm{hPa})$. These results suggest that convection has to become more bottom heavy in order to effectively moisten smaller domain sizes.

The conspicuous absence of top-heavy omega profiles coherent with $\mathrm{LCT}_{E}$ is also an indicator that extensive stratiform clouds are not involved with positive moisture-convection feedbacks on MJO time scales, even for the largest domains. While radiative effectssubsumed by $\mathrm{LCT}_{E}$-could be important to the convection-coupled CWV increases during an MJO active phase (Kim et al. 2015; Del Genio and Chen 2015), the drying effect of stratiform clouds precludes their involvement in column moistening (Chikira 2014; Wolding et al. 2016; Janiga and Zhang 2016). Further investigations are required to examine the precise role of stratiform and anvil clouds in the maintenance of the MJO CWV anomalies (Deng et al. 2016).

HADV is coherent with rising motion in the upper levels $(\sim 300 \mathrm{hPa})$ at the intraseasonal time scales, but it tends to damp CWV increases. The implication for the MJO is that low-frequency HADV drying often follows extensive stratiform rain-consistent with the decaying phase of an MJO event.

While the surface evaporation values did not strongly affect the other terms in the moisture budget on intraseasonal time scales, the strong constant positive forcing from evaporation seen in Figs. 2 and 3 suggests that higher values of CWV may not be sustained over land regions devoid of this forcing. Even if moisture-convection feedbacks are active over land, they have to compensate for the reduced surface evaporation in order to lead to strong convection. This might be a consideration in explaining the weakened amplitude of MJO events over the land surface of the Maritime Continent (Zhang and Hendon 1997; Inness and Slingo 2006).

The results of this study also highlight the multiscale nature of convection-environment interactions in the tropics and caution studies using moisture or MSE budgets to be cognizant of the spatial scale of analysis, which can affect the partitioning of the different budget terms.

Acknowledgments. An insightful review from Brian Mapes and discussions with David Neelin helped improve an early version of this manuscript. Constructive comments from four anonymous reviewers also greatly helped refine the contents of this work. Gridded SMART-R reflectivity and precipitation data are available upon request of the authors. This study was supported by NSF Grant AGS-1062217, and DOE Grants DE-SC0008561 and DE-SC0016245.

\section{APPENDIX}

\section{Power Spectra of the Moisture Budget Terms}

Figure A1 shows the power spectra of the moisture budget terms, excluding $\mathrm{LCT}_{E}(d \mathrm{CWV} / d t$, HADV, and EVAP). At the scale of a radar-sized domain (Fig. A1a), it is clear that the assumption of a red noise background is not reasonable for the CWV tendency term, which has a flatter power spectrum resembling white noise, suggesting that small-scale moisture variations can be captured with a Wiener process in stochastic models (e.g., Stechmann and Neelin 2011). As the area of averaging increases (Figs. A1d,g), spectral peaks emerge with low-frequency peaks at the 24-32-day range for the basin-sized domain. HADV at the radar-sized domain (Fig. A1b) exhibits weak spectral signatures near 5 days and stronger peaks at the array- and basin-sized domains (Figs. A1e,h) corresponding to 32,8 , and 4-5 days. We speculate that the spectral signatures in HADV and EVAP for periods less than 30 days are capturing synoptic variability associated with the mixed Rossby-gravity wave (Yanai and Maruyama 1966; Wallace 1971) and synoptic eddies (Kiranmayi and Maloney 2011)-including tropical depression (TD)-type disturbances (Maloney and Dickinson 2003; Schreck et al. 2011). The low-frequency spectral peak for HADV is closer to 32 days in contrast to the 48-day peak in $\mathrm{LCT}_{E}$ (Fig. 4). Moreover, there is no peak corresponding to the 2-4-day time scale in these terms, suggesting that HADV does not fluctuate strongly in conjunction with the WIG (also confirmed in Fig. 6).

EVAP displays a broad band of enhanced power at the larger domains between 32 and 10 days (Figs. A1f,i), but this really appears to be an artifact of the inadequacy of the first-order autoregressive (AR1) process in capturing the background spectra. Red dashed lines in Fig. A1i, for instance, show the idealized power spectrum of a process whose power varies with frequency as $1 / f^{2.9}$ and therefore drops off more slowly than the power of the AR1 process and appears to better capture the background power spectrum. EVAP on the basin-sized domain is clearly a 

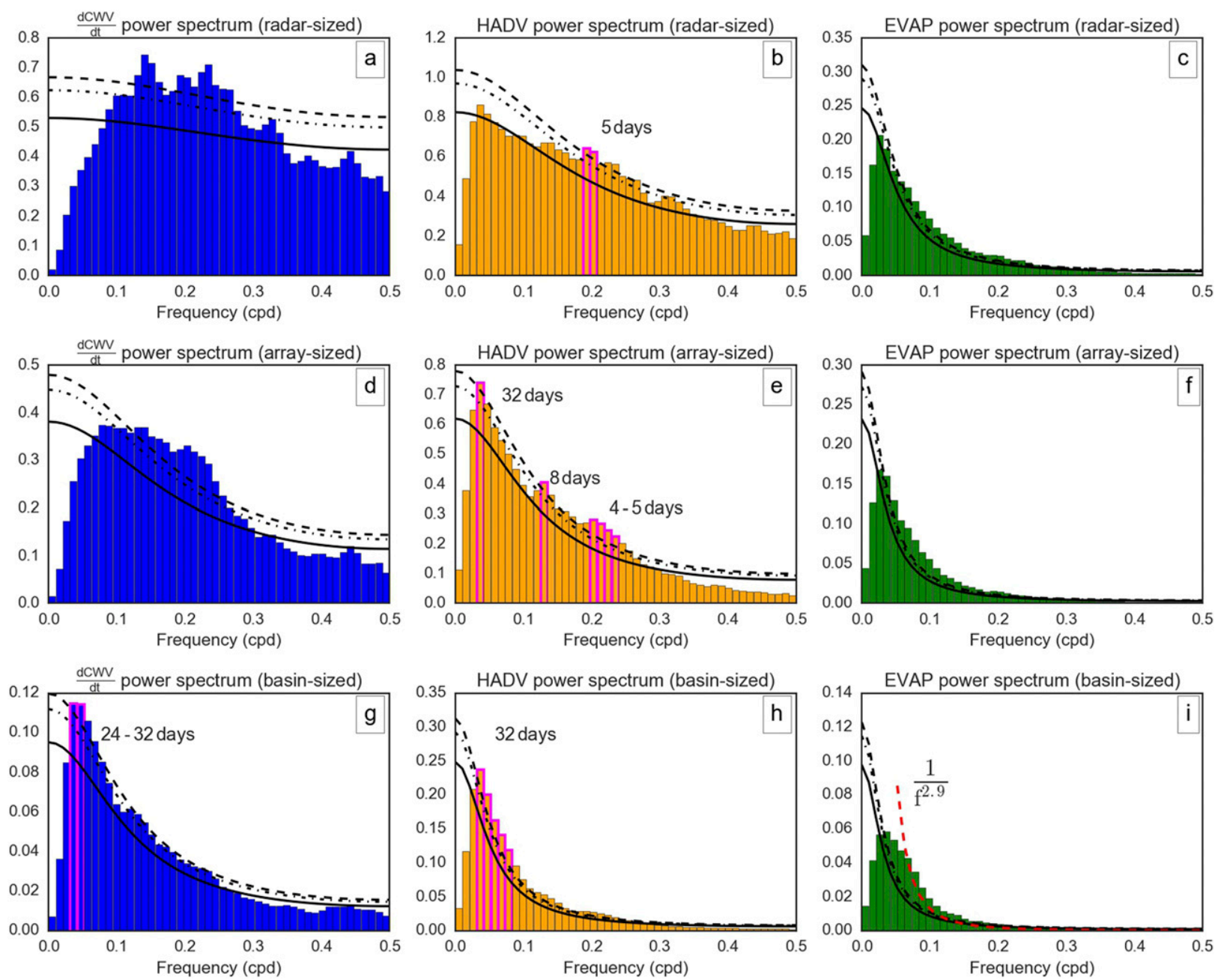

FIG. A1. As in Fig. 3, but for (a),(d),(g) CWV tendency, (b),(e),(h) HADV, and (c),(f),(i) EVAP, averaged over the (a)-(c) radar-, (d)-(f) array-, and (g)-(i) basin-sized domains. The significant peaks in the lower-frequency end are indicated.

field with greater persistence than can be discerned from the use of an AR1 model. For such highly persistent fields, the multiple-filtering method used in Wheeler and Kiladis (1999) might be more useful than the theoretical red spectrum proposed by Masunaga et al. (2006) and Hendon and Wheeler (2008). It could even be argued that the broad band of enhanced power in Fig. A1h is also an artifact of the high levels of persistence in the HADV field at the basin-scale domain.

\section{REFERENCES}

Adames, Á. F., and D. Kim, 2016: The MJO as a dispersive, convectively coupled moisture wave: Theory and observations. J. Atmos. Sci., 73, 913-941, https://doi.org/10.1175/JAS-D-15-0170.1.

Ahmed, F., and C. Schumacher, 2015: Convective and stratiform components of the precipitation-moisture relationship. Geophys. Res. Lett., 42, $10453-10462$, https://doi.org/10.1002/ 2015 GL066957.
—, and — 2017: Geographical differences in the tropical precipitation-moisture relationship and rain intensity onset. Geophys. Res. Lett., 44, 1114-1122, https://doi.org/10.1002/ 2016GL071980.

Andersen, J. A., and Z. M. Kuang, 2012: Moist static energy budget of MJO-like disturbances in the atmosphere of a zonally symmetric aquaplanet. J. Climate, 25, 2782-2804, https://doi. org/10.1175/JCLI-D-11-00168.1.

Benedict, J. J., and D. A. Randall, 2007: Observed characteristics of the MJO relative to maximum rainfall. J. Atmos. Sci., 64 , 2332-2354, https://doi.org/10.1175/JAS3968.1.

Bladé, I., and D. L. Hartmann, 1993: Tropical intraseasonal oscillations in a simple nonlinear model. J. Atmos. Sci, 50, 2922-2939, https:// doi.org/10.1175/1520-0469(1993)050<2922:TIOIAS >2.0.CO;2.

Bretherton, C. S., M. E. Peters, and L. E. Back, 2004: Relationships between water vapor path and precipitation over the tropical oceans. J. Climate, 17, 1517-1528, https://doi.org/ 10.1175/1520-0442(2004)017<1517:RBWVPA > 2.0.CO;2.

Chikira, M., 2014: Eastward-propagating intraseasonal oscillation represented by Chikira-Sugiyama cumulus parameterization. Part II: Understanding moisture variation under weak 
temperature gradient balance. J. Atmos. Sci., 71, 615-639, https://doi.org/10.1175/JAS-D-13-038.1.

Dee, D. P., and Coauthors, 2011: The ERA-Interim reanalysis: Configuration and performance of the data assimilation system. Quart. J. Roy. Meteor. Soc., 137, 553-597, https://doi.org/ 10.1002/qj.828.

Del Genio, A. D., and Y. H. Chen, 2015: Cloud-radiative driving of the Madden-Julian oscillation as seen by the A-Train. J. Geophys. Res. Atmos., 120, 5344-5356, https://doi.org/ 10.1002/2015JD023278.

,,-- D. Kim, and M. S. Yao, 2012: The MJO transition from shallow to deep convection in CloudSat/CALIPSO data and GISS GCM simulations. J. Climate, 25, 3755-3770, https:// doi.org/10.1175/JCLI-D-11-00384.1.

Deng, Q., B. Khouider, A. J. Majda, and R. S. Ajayamohan, 2016: Effect of stratiform heating on the planetary-scale organization of tropical convection. J. Atmos. Sci., 73, 371-392, https:// doi.org/10.1175/JAS-D-15-0178.1.

DePasquale, A., C. Schumacher, and A. Rapp, 2014: Radar observations of MJO and Kelvin wave interactions during DYNAMO/CINDY2011/AMIE. J. Geophys. Res. Atmos., 119, 6347-6367, https://doi.org/10.1002/2013JD021031.

Derbyshire, S. H., I. Beau, P. Bechtold, J. Y. Grandpeix, J. M. Piriou, J. L. Redelsperger, and P. M. M. Soares, 2004: Sensitivity of moist convection to environmental humidity. Quart. J. Roy. Meteor. Soc., 130, 3055-3079, https://doi.org/10.1256/qj.03.130.

Emanuel, K. A., J. D. Neelin, and C. S. Bretherton, 1994: On largescale circulations in convecting atmospheres. Quart. J. Roy. Meteor. Soc., 120,1111-1143, https://doi.org/10.1002/qj.49712051902.

Fu, X., W. Wang, J.-Y. Lee, B. Wang, K. Kikuchi, J. Xu, J. Li, and S. Weaver, 2015: Distinctive roles of air-sea coupling on different MJO events: A new perspective revealed from the DYNAMO/CINDY field campaign. Mon. Wea. Rev., 143, 794-812, https://doi.org/10.1175/MWR-D-14-00221.1.

Fuchs, Z., and D. J. Raymond, 2017: A simple model of intraseasonal oscillations. J. Adv. Model. Earth Syst., 9, 1195-1211, https://doi.org/10.1002/2017MS000963.

Gershunov, A., N. Schneider, and T. Barnett, 2001: Low-frequency modulation of the ENSO-Indian monsoon rainfall relationship: Signal or noise? J. Climate, 14, 2486-2492, https://doi.org/ 10.1175/1520-0442(2001)014<2486:LFMOTE >2.0.CO;2.

Gill, A. E., 1980: Some simple solutions for heat-induced tropical circulation. Quart. J. Roy. Meteor. Soc., 106, 447-462, https:// doi.org/10.1002/qj.49710644905.

Haertel, P. T., and G. N. Kiladis, 2004: Dynamics of 2-day equatorial waves. J. Atmos. Sci., 61, 2707-2721, https://doi.org/ 10.1175/JAS3352.1.

Hagos, S., 2010: Building blocks of tropical diabatic heating. J. Atmos. Sci., 67, 2341-2354, https://doi.org/10.1175/ 2010JAS3252.1.

Hannah, W. M., B. E. Mapes, and G. S. Elsaesser, 2016: A Lagrangian view of moisture dynamics during DYNAMO. J. Atmos. Sci., 73, 1967-1985, https://doi.org/10.1175/JAS-D-15-0243.1.

Hendon, H. H., and M. C. Wheeler, 2008: Some space-time spectral analyses of tropical convection and planetary-scale waves. J. Atmos. Sci., 65, 2936-2948, https://doi.org/10.1175/ 2008JAS2675.1.

Hohenegger, C., and B. Stevens, 2013: Preconditioning deep convection with cumulus congestus. J. Atmos. Sci., 70, 448-464, https://doi.org/10.1175/JAS-D-12-089.1.

Holloway, C. E., and J. D. Neelin, 2009: Moisture vertical structure, column water vapor, and tropical deep convection. J. Atmos. Sci., 66, 1665-1683, https://doi.org/10.1175/2008JAS2806.1.
— and - 2010: Temporal relations of column water vapor and tropical precipitation. J. Atmos. Sci., 67, 1091-1105, https://doi.org/10.1175/2009JAS3284.1.

Houze, R. A., Jr., 1997: Stratiform precipitation in regions of convection: A meteorological paradox? Bull. Amer. Meteor. Soc., 78, 2179-2196, https://doi.org/10.1175/1520-0477(1997) $078<2179$ :SPIROC $>2.0 . \mathrm{CO} ; 2$.

, 2004: Mesoscale convective systems. Rev. Geophys., 42, 43, https://doi.org/10.1029/2004RG000150.

Huffman, G. J., and Coauthors, 2007: The TRMM Multisatellite Precipitation Analysis (TMPA): Quasi-global, multiyear, combined-sensor precipitation estimates at fine scales. J. Hydrometeor., 8, 38-55, https://doi.org/10.1175/JHM560.1.

Inness, P. M., and J. M. Slingo, 2006: The interaction of the Madden-Julian Oscillation with the Maritime Continent in a GCM. Quart. J. Roy. Meteor. Soc., 132, 1645-1667, https:// doi.org/10.1256/qj.05.102.

Inoue, K., and L. Back, 2015: Column-integrated moist static energy budget analysis on various time scales during TOGA COARE. J. Atmos. Sci., 72, 1856-1871, https://doi.org/ 10.1175/JAS-D-14-0249.1.

Janiga, M. A., and C. D. Zhang, 2016: MJO moisture budget during DYNAMO in a cloud-resolving model. J. Atmos. Sci., 73, 2257-2278, https://doi.org/10.1175/JAS-D-14-0379.1.

Johnson, R. H., and P. E. Ciesielski, 2013: Structure and properties of Madden-Julian oscillations deduced from DYNAMO sounding arrays. J. Atmos. Sci., 70, 3157-3179, https://doi.org/ 10.1175/JAS-D-13-065.1.

Kemball-Cook, S. R., and B. C. Weare, 2001: The onset of convection in the Madden-Julian oscillation. J. Climate, 14, 780-793, https:// doi.org/10.1175/1520-0442(2001)014<0780:TOOCIT>2.0.CO;2.

Kerns, B. W., and S. S. Chen, 2014: Equatorial dry air intrusion and related synoptic variability in $\mathrm{MJO}$ initiation during DYNAMO. Mon. Wea. Rev., 142, 1326-1343, https://doi.org/ 10.1175/MWR-D-13-00159.1.

Khouider, B., and A. J. Majda, 2006: A simple multicloud parameterization for convectively coupled tropical waves. Part I: Linear analysis. J. Atmos. Sci., 63, 1308-1323, https://doi.org/ 10.1175/JAS3677.1.

Kim, D., M. S. Ahn, I. S. Kang, and A. D. Del Genio, 2015: Role of longwave cloud-radiation feedback in the simulation of the Madden-Julian oscillation. J. Climate, 28, 6979-6994, https:// doi.org/10.1175/JCLI-D-14-00767.1.

Kiranmayi, L., and E. D. Maloney, 2011: Intraseasonal moist static energy budget in reanalysis data. J. Geophys. Res., 116, D21117, https://doi.org/10.1029/2011JD016031.

Kuang, Z. M., 2008: A moisture-stratiform instability for convectively coupled waves. J. Atmos. Sci., 65, 834-854, https:// doi.org/10.1175/2007JAS2444.1.

_ 2011: The wavelength dependence of the gross moist stability and the scale selection in the instability of column-integrated moist static energy. J. Atmos. Sci., 68, 61-74, https://doi.org/ 10.1175/2010JAS3591.1.

Kumar, V. V., A. Protat, C. Jakob, and P. T. May, 2014: On the atmospheric regulation of the growth of moderate to deep cumulonimbus in a tropical environment. J. Atmos. Sci., 71, 1105-1120, https://doi.org/10.1175/JAS-D-13-0231.1.

Lappen, C. L., and C. Schumacher, 2014: The role of tilted heating in the evolution of the MJO. J. Geophys. Res. Atmos., 119, 29662989, https://doi.org/ https://doi.org/10.1002/2013JD020638.

Lau, W. K. M., and D. E. Waliser, 2012: Intraseasonal Variability in the Atmosphere-Ocean Climate System. 2nd ed. Springer, 613 pp., https://doi.org/10.1007/978-3-642-13914-7. 
Lin, J. L., B. Mapes, M. H. Zhang, and M. Newman, 2004: Stratiform precipitation, vertical heating profiles, and the MaddenJulian oscillation. J. Atmos. Sci., 61, 296-309, https://doi.org/ 10.1175/1520-0469(2004)061<0296:SPVHPA $>2.0$. CO 2 .

Liu, F., G. Huang, and L. C. Feng, 2011: Why do 2-day waves propagate westward? Theor. Appl. Climatol., 106, 443-448, https://doi.org/10.1007/s00704-011-0450-8.

Majda, A. J., and M. G. Shefter, 2001: Models for stratiform instability and convectively coupled waves. J. Atmos. Sci., 58, 1567-1584, https://doi.org/10.1175/1520-0469(2001)058<1567: MFSIAC $>2.0 . \mathrm{CO} ; 2$.

— seasonal oscillations. Proc. Natl. Acad. Sci. USA, 106, 84178422, https://doi.org/10.1073/pnas.0903367106.

Maloney, E. D., and M. J. Dickinson, 2003: The intraseasonal oscillation and the energetics of summertime tropical western North Pacific synoptic-scale disturbances. J. Atmos. Sci., 60, 2153-2168, https:// doi.org/10.1175/1520-0469(2003)060<2153:TIOATE >2.0.CO;2.

Mapes, B. E., 2000: Convective inhibition, subgrid-scale triggering energy, and stratiform instability in a toy tropical wave model. J. Atmos. Sci., 57, 1515-1535, https://doi.org/10.1175/1520-0469 (2000)057<1515:CISSTE $>2.0$. CO;2.

- S. Tulich, J. Lin, and P. Zuidema, 2006: The mesoscale convection life cycle: Building block or prototype for large-scale tropical waves? Dyn. Atmos. Oceans, 42, 3-29, https://doi.org/ 10.1016/j.dynatmoce.2006.03.003.

Masunaga, H., 2012: Short-term versus climatological relationship between precipitation and tropospheric humidity. J. Climate, 25, 7983-7990, https://doi.org/10.1175/JCLI-D-12-00037.1.

, T. S. L'Ecuyer, and C. D. Kummerow, 2006: The MaddenJulian oscillation recorded in early observations from the Tropical Rainfall Measuring Mission (TRMM). J. Atmos. Sci., 63, 2777-2794, https://doi.org/10.1175/JAS3783.1.

Myers, D. S., and D. E. Waliser, 2003: Three-dimensional water vapor and cloud variations associated with the MaddenJulian oscillation during Northern Hemisphere winter. J. Climate, 16, 929-950, https://doi.org/10.1175/1520-0442(2003) 016<0929:TDWVAC $>2.0 . \mathrm{CO} ; 2$.

Neelin, J. D., and I. M. Held, 1987: Modeling tropical convergence based on the moist static energy budget. Mon. Wea. Rev., 115, 3-12, https://doi.org/10.1175/1520-0493(1987) 115<0003:MTCBOT>2.0.CO;2.

- O. Peters, and K. Hales, 2009: The transition to strong convection. J. Atmos. Sci., 66, 2367-2384, https://doi.org/10.1175/ 2009JAS2962.1.

Peters, O., and J. D. Neelin, 2006: Critical phenomena in atmospheric precipitation. Nat. Phys., 2, 393-396, https://doi.org/ 10.1038/nphys314.

Polyakova, E. I., A. G. Journel, I. V. Polyakov, and U. S. Bhatt, 2006: Changing relationship between the North Atlantic Oscillation and key North Atlantic climate parameters. Geophys. Res. Lett., 33, L03711, https://doi.org/10.1029/2005GL024573.

Powell, S. W., 2016: Updraft buoyancy within and moistening by cumulonimbi prior to MJO convective onset in a regional model. J. Atmos. Sci., 73, 2913-2934, https://doi.org/10.1175/ JAS-D-15-0326.1.

— , and R. A. Houze Jr., 2013: The cloud population and onset of the Madden-Julian Oscillation over the Indian Ocean during DYNAMO-AMIE. J. Geophys. Res. Atmos., 118, 1197911 995, https://doi.org/10.1002/2013JD020421.

- and - 2015: Effect of dry large-scale vertical motions on initial MJO convective onset. J. Geophys. Res. Atmos., 120, 4783-4805, https://doi.org/10.1002/2014JD022961.
Raymond, D. J., and Z. Fuchs, 2009: Moisture modes and the Madden-Julian oscillation. J. Climate, 22, 3031-3046, https:// doi.org/10.1175/2008JCLI2739.1.

— S. L. Sessions, A. H. Sobel, and Z. Fuchs, 2009: The mechanics of gross moist stability. J. Adv. Model. Earth Syst., 1 (9), https://doi.org/10.3894/JAMES.2009.1.9.

Riley Dellaripa, E. M., E. Maloney, and S. C. van den Heever, 2018: Wind-flux feedbacks and convective organization during the November 2011 MJO event in a high-resolution model. J. Atmos. Sci., 75, 57-84, https://doi.org/10.1175/ JAS-D-16-0346.1.

Roundy, P. E., 2008: Analysis of convectively coupled Kelvin waves in the Indian Ocean MJO. J. Atmos. Sci., 65, 1342-1359, https://doi.org/10.1175/2007JAS2345.1.

_- and W. M. Frank, 2004: A climatology of waves in the equatorial region. J. Atmos. Sci., 61, 2105-2132, https://doi. org/10.1175/1520-0469(2004)061<2105:ACOWIT>2.0.CO;2.

Ruppert, J. H., and R. H. Johnson, 2015: Diurnally modulated cumulus moistening in the preonset stage of the MaddenJulian oscillation during DYNAMO. J. Atmos. Sci., 72, 16221647, https://doi.org/10.1175/JAS-D-14-0218.1.

Schiro, K. A., J. D. Neelin, D. K. Adams, and B. R. Lintner, 2016: Deep convection and column water vapor over tropical land versus tropical ocean: A comparison between the Amazon and the tropical western Pacific. J. Atmos. Sci., 73, 4043-4063, https://doi.org/10.1175/JAS-D-16-0119.1.

Schreck, C. J., J. Molinari, and K. I. Mohr, 2011: Attributing tropical cyclogenesis to equatorial waves in the western North Pacific. J. Atmos. Sci., 68, 195-209, https://doi.org/10.1175/ 2010JAS3396.1.

Schumacher, C., R. A. Houze Jr., and I. Kraucunas, 2004: The tropical dynamical response to latent heating estimates derived from the TRMM precipitation radar. J. Atmos. Sci., 61, 1341-1358, https://doi.org/10.1175/1520-0469(2004)061<1341: TTDRTL $>2.0 . \mathrm{CO} ; 2$.

Sherwood, S. C., R. Roca, T. M. Weckwerth, and N. G. Andronova, 2010: Tropospheric water vapor, convection, and climate. Rev. Geophys., 48, RG2001, https://doi.org/10.1029/2009RG000301.

Slonosky, V. C., P. D. Jones, and T. D. Davies, 2001: Atmospheric circulation and surface temperature in Europe from the 18th century to 1995. Int. J. Climatol., 21, 63-75, https://doi.org/ 10.1002/joc.591.

Sobel, A., and E. Maloney, 2012: An idealized semi-empirical framework for modeling the Madden-Julian oscillation. J. Atmos. Sci., 69, 1691-1705, https://doi.org/10.1175/JAS-D11-0118.1.

- , and -2013 : Moisture modes and the eastward propagation of the MJO. J. Atmos. Sci., 70, 187-192, https://doi.org/ 10.1175/JAS-D-12-0189.1.

Sobel, A. H., J. Nilsson, and L. M. Polvani, 2001: The weak temperature gradient approximation and balanced tropical moisture waves. J. Atmos. Sci., 58, 3650-3665, https://doi.org/ 10.1175/1520-0469(2001)058<3650:TWTGAA > 2.0.CO;2.

- S. E. Yuter, C. S. Bretherton, and G. N. Kiladis, 2004: Largescale meteorology and deep convection during TRMM KWAJEX. Mon. Wea. Rev., 132, 422-444, https://doi.org/ 10.1175/1520-0493(2004)132<0422:LMADCD>2.0.CO;2.

Sobel, A., S. G. Wang, and D. Kim, 2014: Moist static energy budget of the MJO during DYNAMO. J. Atmos. Sci., 71, 4276-4291, https://doi.org/10.1175/JAS-D-14-0052.1.

Stechmann, S. N., and J. D. Neelin, 2011: A stochastic model for the transition to strong convection. J. Atmos. Sci., 68, 2955-2970, https://doi.org/10.1175/JAS-D-11-028.1. 
Steiner, M., R. A. Houze, and S. E. Yuter, 1995: Climatological characterization of three-dimensional storm structure from operational radar and rain gauge data. J. Appl. Meteor., 34, 1978-2007, https://doi.org/10.1175/1520-0450(1995)034<1978: CCOTDS $>2.0 . \mathrm{CO} ; 2$.

Straub, K. H., and G. N. Kiladis, 2003: The observed structure of convectively coupled Kelvin waves: Comparison with simple models of coupled wave instability. J. Atmos. Sci., 60, 1655-1668, https:// doi.org/10.1175/1520-0469(2003)060<1655:TOSOCC >2.0.CO;2.

Sugiyama, M., 2009: The moisture mode in the quasi-equilibrium tropical circulation model. Part I: Analysis based on the weak temperature gradient approximation. J. Atmos. Sci., 66, 15071523, https://doi.org/10.1175/2008JAS2690.1.

Takayabu, Y. N., 1994: Large-scale cloud disturbances associated with equatorial waves. Part I: Spectral features of the cloud disturbances. J. Meteor. Soc. Japan, 72, 433-449, https://doi. org/10.2151/jmsj1965.72.3_433.

— K. M. Lau, and C. H. Sui, 1996: Observation of a quasi-2-day wave during TOGA COARE. Mon. Wea. Rev., 124, 1892-1913, https:// doi.org/10.1175/1520-0493(1996)124<1892:OOAQDW >2.0.CO;2.

Tompkins, A. M., 2001: Organization of tropical convection in low vertical wind shears: The role of water vapor. J. Atmos. Sci., 58, 529-545, https://doi.org/10.1175/1520-0469(2001) $058<0529$ :OOTCIL $>2.0$. CO 2 .

Wallace, J. M., 1971: Spectral studies of tropospheric wave disturbances in the tropical western Pacific. Rev. Geophys., 9, 557-612, https://doi.org/10.1029/RG009i003p00557.

Wang, B., and H. Rui, 1990: Dynamics of the coupled moist Kelvin-Rossby wave on an equatorial $\beta$-plane. J. Atmos. Sci., 47, 397-413, https://doi.org/10.1175/1520-0469(1990) 047<0397:DOTCMK > 2.0.CO;2.

— , and G. Chen, 2016: A general theoretical framework for understanding essential dynamics of Madden-Julian oscillation. Climate Dyn., 49, 2309-2328, https://doi.org/10.1007/ s00382-016-3448-1.

Wheeler, M., and G. N. Kiladis, 1999: Convectively coupled equatorial waves: Analysis of clouds and temperature in the wavenumberfrequency domain. J. Atmos. Sci., 56, 374-399, https://doi.org/ 10.1175/1520-0469(1999)056<0374:CCEWAO > 2.0.CO;2.

Wolding, B. O., and E. D. Maloney, 2015: Objective diagnostics and the Madden-Julian oscillation. Part II: Application to moist static energy and moisture budgets. J. Climate, 28, 77867808, https://doi.org/10.1175/JCLI-D-14-00689.1.

$\longrightarrow, \ldots$, and M. Branson, 2016: Vertically resolved weak temperature gradient analysis of the Madden-Julian oscillation in SP-CESM. J. Adv. Model. Earth Syst., 8, 1586-1619, https:// doi.org/10.1002/2016MS000724.

Yanai, M., and T. Maruyama, 1966: Stratospheric wave disturbances propagating over the equatorial Pacific. J. Meteor. Soc. Japan, 44, 291-294, https://doi.org/10.2151/jmsj1965.44.5_291.
— S. Esbensen, and J. H. Chu, 1973: Determination of bulk properties of tropical cloud clusters from large-scale heat and moisture budgets. J. Atmos. Sci., 30, 611-627, https://doi.org/ 10.1175/1520-0469(1973)030<0611:DOBPOT >2.0.CO;2.

Yasunaga, K., and B. Mapes, 2012a: Differences between more divergent and more rotational types of convectively coupled equatorial waves. Part I: Space-time spectral analyses. J. Atmos. Sci., 69, 3-16, https://doi.org/10.1175/JAS-D-11-033.1.

— rotational types of convectively coupled equatorial waves. Part II: Composite analysis based on space-time filtering. J. Atmos. Sci., 69, 17-34, https://doi.org/10.1175/JAS-D-11-034.1.

Yoneyama, K., C. D. Zhang, and C. N. Long, 2013: Tracking pulses of the Madden-Julian oscillation. Bull. Amer. Meteor. Soc., 94, 1871-1891, https://doi.org/10.1175/BAMS-D-12-00157.1.

Yu, J.-Y., and J. D. Neelin, 1994: Modes of tropical variability under convective adjustment and the Madden-Julian oscillation. Part II: Numerical results. J. Atmos. Sci., 51, 1895-1914, https://doi.org/ 10.1175/1520-0469(1994)051<1895:MOTVUC > 2.0.CO;2.

Zelinka, M. D., and D. L. Hartmann, 2009: Response of humidity and clouds to tropical deep convection. J. Climate, 22, 23892404, https://doi.org/10.1175/2008JCLI2452.1.

Zermeno-Diaz, D. M., C. D. Zhang, P. Kollias, and H. Kalesse, 2015: The role of shallow cloud moistening in MJO and nonMJO convective events over the ARM Manus site. J. Atmos. Sci., 72, 4797-4820, https://doi.org/10.1175/JAS-D-14-0322.1.

Zhang, C. D., 2005: Madden-Julian Oscillation. Rev. Geophys., 43, RG2003, https://doi.org/10.1029/2004RG000158.

— , and H. H. Hendon, 1997: Propagating and standing components of the intraseasonal oscillation in tropical convection. J. Atmos. Sci., 54, 741-752, https://doi.org/10.1175/1520-0469 (1997)054<0741:PASCOT >2.0.CO;2.

Zhang, G. J., and X. L. Song, 2009: Interaction of deep and shallow convection is key to Madden-Julian Oscillation simulation. Geophys. Res. Lett., 36, L09708, https://doi.org/10.1029/ 2009GL037340.

Zhang, M. H., and J. L. Lin, 1997: Constrained variational analysis of sounding data based on column-integrated budgets of mass, heat, moisture, and momentum: Approach and application to ARM measurements. J. Atmos. Sci., 54, 1503-1524, https://doi.org/10.1175/1520-0469(1997)054<1503: CVAOSD $>2.0 . \mathrm{CO} ; 2$.

, R. T. Cederwall, J. J. Yio, and S. C. Xie, 2001: Objective analysis of ARM IOP data: Method and sensitivity. Mon. Wea. Rev., 129, 295-311, https://doi.org/10.1175/1520-0493(2001) 129<0295:OAOAID > 2.0.CO;2.

Zipser, E. J., 1977: Mesoscale and convective-scale downdrafts as distinct components of squall-line structure. Mon. Wea. Rev., 105, 1568-1589, https://doi.org/10.1175/1520-0493(1977) $105<1568$ :MACDAD $>2.0 . \mathrm{CO} ; 2$ 